\title{
WHY DID SPONSOR BANKS RESCUE THER SIVS? A SIGNAUNG MODEL OF RESCUES
}

\author{
Anatoli Segura
}

CEMFI Working Paper No. 1402

May 2014

\author{
CEMFI
}

Casado del Alisal 5; 28014 Madrid

Tel. (34) 914290551 Fax (34) 914291056

Internet: www.cemfi.es

\begin{abstract}
I am especially indebted to Javier Suarez for continuous support and advice during this project. I thank Gara Afonso, Guillermo Caruana, Douglas Gale, Itay Goldstein, Gerard Llobet, David Martinez-Miera, Guillermo Ordoñez, Cecilia Parlatore, Rafael Repullo, Philipp Schnabl and Sergio Vicente, as well as seminar audiences at CEMFI, Wharton, NYU, University of Amsterdam, Vienna IHS, Bank of England, Bank of Spain, ECB, Copenhagen Business School, Fed Board, University of Texas at Austin, Banca d'Italia and HSE Moscow for helpful comments. I acknowledge support from a doctoral grant of the AXA Research Fund.
\end{abstract}


CEMFI Working Paper 1402

May 2014

\title{
WHY DID SPONSOR BANKS RESCUE THER SIVS? A SIGNAUNG MODEL OF RESCUES
}

\begin{abstract}
At the beginning of the past financial crisis sponsoring banks rescued their structured investment vehicles (SIVs) despite of lack of contractual obligation to do so. I show that this outcome may arise as the equilibrium of a signaling game between banks and their debt investors when a negative shock affects the correlated asset returns of a fraction of banks and their sponsored vehicles. The rescue is interpreted as a good signal and reduces the refinancing costs of the sponsoring bank. If banks' leverage is high or the negative shock is sizable enough, the equilibrium is a pooling one in which all banks rescue. When the aggregate financial sector is close to insolvency, banks' expected net worth would increase if rescues were banned. The model can be extended to discuss the circumstances in which all banks collapse after rescuing their vehicles.
\end{abstract}

JEL Codes: G2, G3.

Keywords: Reputation risk, rescues, mispricing, implicit support, shadow banking system.

Anatoli Segura

CEMFI

segura@cemfi.es 


\section{Introduction}

The 2007-2009 financial crisis was rife with situations in which banks provided support beyond their contractual obligations to sponsored entities in the shadow banking system. A prominent example occurred in the structured investment vehicles (SIVs) industry. These off-balance sheet conduits experienced problems to refinance their maturing debt due to investors' concerns on their exposure to subprime losses. ${ }^{1}$ When the whole industry was at the eve of default, most sponsor banks stepped in and rescued their SIVs even though they were not contractually obliged to do so.

Commentators and regulators attributed these and similar voluntary support decisions to the reputational concerns of the sponsors. The following quote on HSBC's rescue of its two SIVs is a clear example of how these events were interpreted:

"HSBC's motivation appears to be fear of the unknown. A huge SIV failure, especially if it triggered losses for the holders of its commercial paper, would be a reputational black eye. At the extreme, the financial consequences could be an increase in the bank's perceived riskiness as well as a higher cost of funding in the capital markets." Financial Times, November 28, 2007 [emphasis mine].

In addition, the potential negative impact of these rescues on bank capitalization opened a debate on the regulation of implicit support and "reputational risk" in banking. And as a result there is currently a regulatory move towards limiting or prohibiting some transactions between depository institutions and their sponsored entities in the shadow banking system. In particular, both under the final implementation of the Volcker Rule in the US and of the proposals of the Vickers Commission in the UK, banks will not be allowed to give support to their sponsored unguaranteed vehicles. ${ }^{23}$ In the EU, the proposals of the Liikanen report

\footnotetext{
${ }^{1} \mathrm{SIVs}$ debt consisted of asset backed commercial paper (ABCP) and medium term notes (MTN) in a typical ratio 2 to 5 . Explicit debt guarantees from the sponsor covered no more than $30 \%$ of the ABCP, while MTNs were not guaranteed at all. For a description of the reasons why off-balance sheet conduits suffered refinancing problems in the second half of 2007, see Brunnermeier (2009) and Gorton (2010).

${ }^{2}$ In the US, Section 619 of the Dodd-Frank Act, commonly known as the Volcker Rule, adds a new section 13 to the Bank Holding Company Act of 1956 whose final text was issued by the federal banking agencies in December 10, 2013. Appart from prohibiting banking entities from engaging in proprietary trading and from acquiring ownership interests in funds, the new section also prohibits them from entering into transactions with funds for which they serve as investment advisers and in particular to rescue them.

${ }^{3}$ In the UK, the proposals of the Independent Commission on Banking, commonly kwown as Vickers
} 
(2012) also point towards prohibiting these forms of voluntary support.

Yet, the precise nature of the reputational risk and why voluntary support decisions may weaken the banks is not obvious. In fact, the existing literature predicts that sponsors will not give support during a severe downturn (Gorton and Souleles, 2006, Ordoñez, 2013, and Parlatore, 2013). So, why did sponsor banks rescue their SIVs? What reputation was at stake and why was it so valuable during a crisis? And finally, should regulators have intervened and banned these rescues in order to protect the banking system?

To address these questions, this paper develops a signaling model that explains banks' voluntary rescue of their sponsored vehicles in the midst of a crisis. Although the theory may also apply to other sponsored entities such as money market funds or hedge funds, the model focuses, for concreteness, on the rescues of SIVs. ${ }^{4}$ Banks and their sponsored vehicles have long-term assets and short-term debt to be refinanced. At the initial date a negative aggregate shock affects the assets held by some of the banks and their vehicles and divides the bank-vehicle pairs into two types, say, good and bad. Crucially, the arrival of the aggregate shock is public information but the type of a pair bank-vehicle is private information of the bank. The negative shock is bad enough to trigger a run on all vehicles in spite of the fact that good vehicles are fundamentally solvent (i.e. with perfect information they would be able to refinance their debt). In this context, banks face a decision on whether to rescue their vehicles taking into account its non-trivial impact on the cost of refinancing their own debt. Banks finance these rescues by raising new debt that in the baseline model is assumed to be junior to banks' preexisting debt.

Two results drive the types of equilibria that may arise in this economy. First, debt issued by a good bank is fundamentally more valuable. So, the pricing of debt depends on investors' beliefs on the quality of the issuer and any non fully separating equilibrium involves

Commission, have been enacted on December 18, 2013 by the Financial Services (Banking Reform) Act 2013. This regulatory reform limits the exposure of depository institutions to other financial entities within the same bank holding company (BHC). In particular, transactions between a regulated commercial bank and entities within the $\mathrm{BHC}$ will have to be conducted in market terms, which rules out voluntary support to these entities when they suffer financial distress.

${ }^{4}$ For a detail account of the rise, demise, and rescue of the SIVs industry, see Appendix A. Brady et al. (2012) and Kacperczyk and Schnabl (2012) document the relevance of sponsor support in the money market fund industry during the past financial crisis. The rescue by Bear Stearns of two of its hedge funds in July 2007 was largely covered by the media. 
some debt overpricing benefits for bad banks. Second, good banks have higher incentives to rescue their vehicles than bad banks. As a result, the decision to rescue is interpreted by the investors as a good signal.

I show that in equilibrium all good banks rescue their vehicles because, on the one hand, they have fundamental motives to do so (their vehicles are solvent but illiquid due to imperfect information), and, on the other, this decision is also interpreted as a good signal by debt investors. Bad banks trade off the fundamental costs of rescuing their (bad) vehicles with the debt overpricing benefits of keeping their own type unrevealed. The debt overpricing benefits of the rescue are increasing in the market expectation on the quality of a rescuing bank, which leads to a unique equilibrium that can be of three types: pooling in which all banks rescue, semiseparating in which good banks and a fraction of bad banks rescue, and separating in which only good banks rescue.

The model predicts the pooling equilibrium to arise when either banks' debt is very large or the return of the assets held by bad institutions is very low. Both conditions were likely satisfied in 2007. First, banks were highly levered and an important fraction of their debt had to be regularly refinanced in wholesale markets due to its very short maturity (interbank loans, commercial paper, repos). Second, the subprime crisis meant a severe downward updating of the fundamental value of some of the backing assets.

Regulators have manifested concern about the risk these rescues pose to the banking system and the new regulatory frameworks in most jurisdictions will ban these actions in the future. In the context of my model, I analyze the effects of the introduction of a ban on rescues. In a pooling equilibrium, the ban reduces the welfare of vehicles' debtholders to the same extent that it increases the average net worth of banks since it avoids the rescue of vehicles which are on average insolvent. The net worth of bad banks always increases as a result of the ban and, interestingly, when the aggregate financial sector is close to insolvency, the net worth of good banks increases as well. ${ }^{5}$ The last effect arises because in a pooling equilibrium good banks not only subsidy the refinancing of bad banks but also end up subsidizing the rescue of bad vehicles. The latter constitutes an additional cost for good banks that dominates the fundamental benefits from rescuing their illiquid vehicles when the

\footnotetext{
${ }^{5}$ I say that the aggregate financial sector is solvent (insolvent) when the difference between the aggregate expected payoff of its assets and the face value of maturing debt is positive (negative).
} 
aggregate financial sector is close to insolvency. In a separating equilibrium, the effects of a ban are reversed: vehicles' debtholders average welfare increases whereas banks' average net worth decreases.

Central banks played an instrumental role in making the rescues of SIVs possible. In December 12, 2007 the Federal Reserve and the European Central Bank entered into an emergency currency swap line in order for the latter to be able to lend dollars to European banks that had lost access to dollar denominated interbank markets and were in need of this currency to support their SIVs (and also similar explicitly guaranteed ABCP conduits). ${ }^{6}$ Central bank lending is secured and thus de facto senior to other forms of financing. In an extension of the model I analyze the effect of allowing for this seniority for the financing of the rescue with respect to banks' preexisting debt. I find that when the aggregate financial sector is insolvent this relative seniority is key for the nature of the equilibrium. ${ }^{7}$ When new financing is junior, banks try to rescue their vehicles but investors refuse to supply the additional funds, rescues are not completed and vehicles fail. However, when new financing is senior, banks obtain financing for the rescues in a first stage but then they are not able to refinance their own debt, leading to a systemic collapse. This result identifies a new channel through which the seniority privileges of central bank lending (or other forms of lending) may propagate distress through the financial system and calls for central banks to closely monitor banks' use of the funds they provide during liquidity crises.

In another extension of the model I allow each bank to sponsor several vehicles with and without explicit support guarantees. ${ }^{8}$ I show that if vehicles suffer a run and sponsors are contractually obliged to rescue some of them, they have greater incentives to voluntarily support the rest. This complementarity between contractual and voluntary support may be yet an additional reason why banks rescued their SIVs in the crisis.

Related literature This paper belongs to the theoretical literature that has analyzed voluntary support from sponsoring institutions. The existing papers share the prediction

\footnotetext{
${ }^{6}$ See Fleming and Klagge (2010).

${ }^{7}$ When the aggregate financial sector is solvent this relative seniority is irrelevant in equilibrium.

${ }^{8}$ As an example, in 2007 Citigroup was the sponsor of nine fully supported ABCP conduits and seven non explicitly supported SIVs.
} 
-contrary to my model- that a rescue is less likely under adverse economic circumstances. ${ }^{9}$ In Ordoñez (2013) the support decision is based on reputational concerns. He assumes the reputational benefits of support to be increasing in the value of new investment opportunities, which means that sponsors are less likely to support their subsidiaries after a severe deterioration of the economy. In Gorton and Souleles (2006) voluntary support arises as a form of collusion between sponsors and investors in conduits in a repeated context. ${ }^{10}$ Since collusion is sustained by the value of future collaboration, banks have less incentives to rescue their vehicles in the midst of an economic crisis. Finally, Parlatore (2013) builds a model of delegated portfolio management in which the sponsor obtains fees that are proportional to the market price of assets under management and thus its incentives to support a subsidiary are reduced after a negative shock.

My paper is also connected to earlier contributions in which signaling concerns interact with debt dilution costs. ${ }^{11}$ In John and Nachman (1985) reputation, understood as information about a firm's type, affects the debt dilution costs associated to the financing of future investment oportunities. They show that reputation concerns reduce the debt overhang problem identified by Myers (1977). In Diamond (1991) reputation built over time reduces a moral hazard problem and allows firms to switch from banks' monitored finance to unmonitored market finance.

The interaction between reputation concerns and transfers of value among security holders has also been found in other corporate finance contexts. In Boot, Greenbaum and Thakor (1993) a firm complies with an unenforceable financial contract in order to improve investors' perception on its capability to satisfy (similar) contracts in the future. In Thakor (2005) banks screen borrowers before offering them loan commitments that could be withdrawn under material adverse change clauses. He shows that during booms banks do not refuse lending to bad projects in order to preserve their screening reputation.

\footnotetext{
${ }^{9}$ In my model the existence of the shadow banking system is taken as given. Recent theoretical work about the emergence and fragility of shadow banks includes Parlour and Plantin (2008), Dang, Gorton and Holmström (2012) and Gennaioli, Shleifer and Vishny (2013). (See the latter for a survey of this literature).

${ }^{10}$ The same mechanism leads banks to rescue borrowers in distress in Dinc (2000).

${ }^{11}$ The influential paper of Myers and Majluf (1984) gave raise to a literature where security design was directed to reduce the dilution costs associated with asymmetric information (see e.g. Nachman and Noe, 1994, DeMarzo and Duffie, 1999, Fulghieri and Lukin, 2001).
} 
The paper is organized as follows. Section 2 presents the ingredients of the model. Section 3 finds the equilibrium of the model and discusses how changes of parameters affect it. Section 4 analyzes the welfare effects of a ban on rescues. Section 5 extends the model along several dimensions and discusses the robustness of the results. Section 6 concludes. Appendix A describes the SIV industry and reviews the events that led sponsor banks to rescue these vehicles in the recent crisis. All proofs are in Appendix B.

\section{The model}

There are two dates $t=0,1$, and two classes of agents in the economy: bankers and investors. Every banker owns a bank, and every bank sponsors a vehicle.

\section{$2.1 \quad$ Bankers}

There is a continuum of measure one of bankers. Bankers maximize the expected value of their terminal wealth. Each banker owns a bank with asset size $Z$ and each bank sponsors a vehicle with asset size 1 . Banks and vehicles have preexisting debt of face value $D_{B}$ and $D_{S}$, respectively, that they need to refinance at $t=0$. The bank is the residual claimant of its vehicle, subject to limited liability. And bankers are the residual claimants of banks, also subject to limited liability. The sponsor bank has not granted any contractual guarantees to its vehicle, i.e. it is not at all obliged by the debts of its vehicle.

Prior to $t=0$, all banks and vehicles invested in ex ante identical assets. But at $t=0$ a negative shock affects the assets of a fraction $1-\alpha$ of the bank-vehicle pairs that as a result become $\operatorname{bad}(j=b)$ while the assets of the unaffected fraction $\alpha$ remain $\operatorname{good}(j=g) .{ }^{12}$ The type of the pair bank-vehicle is private information of the banker who owns the corresponding bank.

\footnotetext{
${ }^{12}$ I capture in this simple way positive correlation on the quality of the assets held by banks and their sponsored vehicles. The correlation may arise because: banks held junior tranches of the securitized assets they originated and sold to their vehicles; when the crisis started banks held on balance sheet pools of loans yet to be securitized that were similar to pools of loans already securitized and sold to their vehicles; in Fall 2007 banks were forced to rescue explicitly guaranteed ABCP conduits whose assets were similar to those held by SIVs. As discussed in Section 5.4 the model works as well if the type of the bank determines the quality of the vehicle's asset and also of a fraction of the assets on the bank balance sheet, while the quality of the assets on the rest of the bank balance sheet is public information.
} 
The gross return at $t=1$ of the assets of type $j=g, b$ is a random variable $Y_{j}$ with support $[0,+\infty)$ and pdf $f_{j}(y)>0$ for all $y>0 . Y_{g}$ dominates $Y_{b}$ in the sense of the strictly monotone likelihood ratio (MLR) property:

$$
Y_{g} \underset{M L R}{\succ} Y_{b} \Leftrightarrow \frac{f_{g}\left(y_{2}\right)}{f_{b}\left(y_{2}\right)}>\frac{f_{g}\left(y_{1}\right)}{f_{b}\left(y_{1}\right)} \text { for all } y_{2}>y_{1} .
$$

Accordingly, high returns are relatively more likely when the asset is good, and this is more so the higher the returns are. MLR dominance implies in particular that $Y_{g}$ strictly first order stocastically dominates $Y_{b}$ and, thus, $E\left[Y_{g}\right]>E\left[Y_{b}\right]$.

\subsection{Investors}

At $t=0$ there is a large number of risk-neutral investors with deep pockets that require an expected rate of return on their funds normalized to zero. They compete for buying debt issued by either banks or vehicles. Some of them hold banks and vehicles' maturing debt. In case a bank or vehicle is not able to refinance its debt, the institution fails and debtholders take ownership of its assets in a frictionless manner. ${ }^{13}$

\subsection{Sequence of events after a run on the vehicles}

I will focus on a situation in which vehicles are not able to refinance their debt at $t=0$. Since investors do not observe vehicles' types, such inability arises when the unconditional expected payoff of a vehicle is lower than the value of its debt:

Assumption $1 \alpha E\left[Y_{g}\right]+(1-\alpha) E\left[Y_{b}\right] \leq D_{S} \cdot{ }^{14}$

The assumption implies in particular that $E\left[Y_{b}\right]<D_{S}$, so that bad vehicles are fundamentally insolvent.

Regarding the banking sector, I assume that banks are on average solvent since otherwise they would also be unable to refinance their debt:

\footnotetext{
${ }^{13}$ Introducing bankruptcy costs would only affect the analysis of the distributional welfare effects of a ban on vehicles rescues (see Section 4) by adding an additional cost of this policy for vehicles' debtholders.

${ }^{14}$ As a matter of terminology throughout the paper, when the expected value of the assets of an institution (bank or vehicle) is just equal to the face value of debt it has to refinance I say that the institution is insolvent. The rationale is that there is no finite promised repayment it could offer investors so that they would be willing to refinance its debt.
} 
Assumption $2 Z\left(\alpha E\left[Y_{g}\right]+(1-\alpha) E\left[Y_{b}\right]\right)>D_{B}$.

In addition I make two additional assumptions that simplify the characterization of possible equilibria: ${ }^{15}$

Assumption $3 E\left[Y_{g}\right]>D_{S}$.

Assumption $4 Z \geq \frac{1-\alpha}{\alpha}$.

Assumption 3 states that good vehicles are fundamentally solvent. ${ }^{16}$ Assumption 4 imposes a rather mild lower bound on the relative size of banks with respect to their vehicles. ${ }^{17}$

When vehicles are unable to refinance their debt, banks may voluntarily rescue them. In the baseline model I assume that the rescue cannot be funded by diluting the preexisting bank debtholders. ${ }^{18}$ So, when the rescue occurs, I consider it as part of a refinancing arrangement between the bank, the vehicle and (new) debt investors whereby the latter provide the funds needed to repay both the bank and its vehicle's maturing debt, $D_{B}$ and $D_{S}$, while the vehicle's asset is transferred to the bank. The sequence of events at $t=0$, represented in Figure 1, is as follows:

1. Every bank chooses between rescuing its vehicle $(a=1)$ and not rescuing it $(a=0)$.

2. For every $a \in\{0,1\}$ investors ask a promised repayment scheme $R_{a}$ based on their beliefs $p_{a} \in[0,1]$ on the probability that a bank is good conditional on its decision $a$. Specifically:

(a) For $a=0$ investors set a repayment $R_{0}$ in exchange for providing the funds $D_{B}$ the bank needs for its own refinancing. I write $R_{0}=\infty$ if investors are not willing to supply them.

\footnotetext{
${ }^{15}$ In Section 5.4 I discuss the effect of relaxing these assumptions.

${ }^{16}$ Assumption 1 and 3 imply that the fraction of bad types is sufficiently high:

$$
1-\alpha \geq \frac{E\left[Y_{g}\right]-D_{S}}{E\left[Y_{g}\right]-E\left[Y_{b}\right]}>0
$$

${ }^{17}$ For $\alpha \geq .5$ it only imposes that $Z \geq 1$, i.e. that the asset size of banks is no lower than that of their vehicles.

${ }^{18}$ In other words, $D_{B}$ is senior to any debt that could be raised to refinance $D_{S}$.
} 


\begin{tabular}{|c|c|c|}
\hline $\begin{array}{l}\text {-Vehicles find out that they } \\
\text { will be unable to refinance } \\
\text { their maturing debt } \\
\text {-Banks announce whether } \\
\text { or not they want to rescue } \\
\text { their vehicles }\end{array}$ & $\begin{array}{l}\text {-Competitive investors } \\
\text { observe decisions and ask } \\
\text { promised repayment in } \\
\text { order to finance banks } \\
\text { [Investors may refuse to } \\
\text { supply the funds banks } \\
\text { need to rescue their } \\
\text { vehicles] }\end{array}$ & $\begin{array}{l}\text {-Creditors take ownership } \\
\text { of institutions that fail to } \\
\text { refinance their maturing } \\
\text { debt }\end{array}$ \\
\hline
\end{tabular}

Figure 1: Sequence of events at $t=0$

(b) For $a=1$ investors set $R_{1}=\left(R_{1, F}, R_{1, N F}\right)$ where $R_{1, F}$ is the repayment set in exchange for financing $D_{B}+D_{S}$ (which allows to conclude the rescue) and $R_{1, N F}$ is the repayment set for financing only $D_{B}$. Again, I use the convention $R_{1, F}=\infty$ and $R_{1, N F}=\infty$ to represent the cases in which investors are unwilling to finance $D_{B}+D_{S}$ and $D_{B}$, respectively. If $R_{1, F}<\infty$ then investors are willing to finance the rescue (and refinance the bank) and $R_{1, N F}$ is irrelevant. If $R_{1, F}=\infty$ then investors are not willing to finance the rescue and $R_{1, N F}$ is the repayment set in order to refinance only the bank. ${ }^{19}$

3. Institutions that fail to refinance their maturing debt default. Their creditors take ownership of their assets and become the only claimants on their payoffs at $t=1$.

At $t=1$ the non-liquidated institutions distribute the payoff of their assets to their stakeholders following the standard priority rules.

\section{Equilibrium}

Banks and investors play a sequential game with imperfect information. The concept of equilibrium is Perfect Bayesian Equilibrium (PBE) cum the refinement D1 of Cho and Kreps (1987). Thus equilibrium consists of a tuple $\left(\left(a_{j}^{*}\right),\left(R_{a}^{*}\right),\left(p_{a}^{*}\right)\right)$ of (possibly mixed) actions $\left(a_{j}^{*}\right)$

\footnotetext{
${ }^{19}$ This setup is equivalent to the following sequence of events: first, banks try to issue junior debt in order to finance the rescue; after that, banks try to refinance their existing debt.
} 
for every bank type $j$, some required promised schemes $\left(R_{a}^{*}\right)$ set by investors and some beliefs $\left(p_{a}^{*}\right)$ for investors, such that:

1. Banks' sequential rationality: For $j \in\{g, b\}, a_{j}^{*}$ is optimal for a bank of type $j$ given $\left(R_{a}^{*}\right)$.

2. Investors' competitive rationality: For $a \in\{0,1\}, R_{a}^{*}$ sets the lowest repayments for which investors break even given $p_{a}^{*}$. In every case, if no break-even repayment exists, the corresponding $R_{0}^{*}, R_{1, F}^{*}$ or $R_{1, N F}^{*}$ is set equal to $\infty$.

3. Belief consistency: If $a \in\{0,1\}$ is on the equilibrium path, $p_{a}^{*}$ is determined by Bayes' rule.

4. Refinement D1: If $a \in\{0,1\}$ is off-equilibrium, $p_{a}^{*}$ satisfies refinement D1, i.e. if there exists $j \in\{g, b\}$ such that for $j^{\prime} \neq j$ the following strict set inclusion is satisfied:

$$
\begin{aligned}
& \left\{R_{a}: \text { bank } j \text { weakly prefers to deviate from equilibrium to } a\right\} \subsetneq \\
& \subsetneq\left\{R_{a}: \text { bank } j^{\prime} \text { weakly prefers to deviate from equilibrium to } a\right\}
\end{aligned}
$$

then $p_{a}^{*}=1$ if $j=b$ and $p_{a}^{*}=0$ if $j=g$.

The first three equilibrium conditions correspond to PBE. This equilibrium concept imposes no restriction on investors' beliefs off-equilibrium, which generally leads to multiplicity of equilibria. Refinements that impose investors' beliefs to be "reasonable" when they observe off-equilibrium actions narrow down the equilibrium set. Refinement D1, which is a simple and common refinement in the signaling literature, is sufficient for uniqueness of equilibrium in my model in most of the parameter regions. ${ }^{20}$ The intuition behind this refinement is that off-equilibrium beliefs should be based on identifying the types that have the most to gain from deviating from equilibrium.

Before solving the game between banks and investors I discuss next as a benchmark the economy with perfectly informed investors.

\footnotetext{
${ }^{20}$ In the context of financing decisions with asymmetric information, D1 has been used in, for example, Nachman and Noe (1994) and DeMarzo and Duffie (1999). Refinement D1 is a stronger refinement than both the Intuitive Criterion (Cho and Kreps, 1987) and Divinity (Banks and Sobel, 1987), which are insufficient to ensure uniqueness in my model.
} 


\subsection{The perfect information benchmark}

Assumption 3 states that a good vehicle is fundamentally solvent and therefore it is able to refinance its debt and to generate an expected residual payoff to bankers of $E\left[Y_{g}\right]-D_{S}>0$ at $t=0$. On the other hand, Assumption 1 implies that a bad vehicle is fundamentally insolvent and thus unable to refinance its debt. Under perfect information, a bad bank would not raise additional debt in order to rescue its vehicle because doing so would be detrimental to its owners whose expected payoff would decline in $D_{S}-E\left[Y_{b}\right]>0$. As a result, bad vehicles would fail.

\subsection{Asymmetric information and debt mispricing}

To analyze the impact of asymmetric information on debt pricing, condider a bank of type $j \in\{g, b\}$ holding some generic $X>0$ units of its asset and with debt that promises to pay $R$ at $t=1$. Let the expected payoff of this debt be denoted by

$$
V_{j}(X, R):=\int_{0}^{\infty} \min \{X y, R\} f_{j}(y) d y .
$$

Since the return $Y_{g}$ first order stochastically dominates $Y_{b}$ we have

$$
V_{g}(X, R)>V_{b}(X, R)
$$

so the debt issued by a good bank has a greater expected payoff than that issued by a bad bank. Intuitively, this happens because bad banks default more frequently. If investors' belief on the probability that the bank is good is $p$, the valuation of its debt will be

$$
V(X, R, p)=p V_{g}(X, R)+(1-p) V_{b}(X, R)
$$

Henceforth, the promised repayment $R$ that investors would ask in order to provide $D$ units of funds to the bank at $t=0$ satisfies

$$
V(X, R, p)=D
$$

Let $R(X, D, p)$ denote the solution to the equation above, if it exists, and adopt the convention $R(X, D, p)=\infty$ when it does not exist. Clearly, $R(X, D, p)$ is strictly decreasing in $X$ and $p$, and strictly increasing in $D$. 
The expected net worth of the bank when it has to obtain $D$ units of debt funding is

$$
\Pi_{j}(X, D, p)=\int_{0}^{\infty}(X y-R(X, D, p))^{+} f_{j}(y) d y .
$$

Note that the convention $R(X, D, p)=\infty$ implies $\Pi_{j}(X, D, p)=0$ when the bank is not able to finance the $D$ units of funds it requires (and fails).

Finally, it is useful to define the debt mispricing as

$$
M_{j}(X, D, p):=D-V_{j}(R(X, D, p), X) .
$$

The following lemma summarizes the properties of the debt mispricing and its effect on banks' expected net worth:

Lemma 1 The expected net worth of a bank of type $j \in\{g, b\}$ that has $X>0$ units of its asset and has to raise $D$ units of debt when investors' belief on its quality is $p$ is:

$$
\Pi_{j}(X, D, p)=X E\left[Y_{j}\right]-D+M_{j}(X, D, p) .
$$

Assume $R(X, D, p)<\infty$. Then the mispricing $M_{b}(X, D, p)$ of bad banks' debt is strictly positive if $p>0$ and 0 if $p=0$, and is strictly increasing in $p$. If $p>0$ it is strictly increasing in $D$ with slope strictly less than 1 , and strictly decreasing in $X$. The mispricing $M_{g}(X, D, p)$ of good banks' debt is strictly negative if $p<1$ and 0 if $p=1$, and is strictly increasing in $p$. If $p<1$ it is strictly decreasing in $D$, and strictly increasing in $X$.

The lemma states that when banks are able to obtain financing bad (good) banks' debt is overpriced (underpriced), which increases (decreases) their expected net worth relative to the perfect information case. From the perspective of bad banks, as $p$ increases investors' misperception on their type increases and thus also the overpricing $M_{b}(X, D, p)$ of their debt. The opposite happens with the underpricing $-M_{g}(X, D, p)$ of good banks' debt.

When the promised repayment $R$ on debt increases, investors get a higher repayment only on non default states. Since high returns are more likely to happen for the good bank, the expected payoff of the debt issued by a good bank grows faster than that issued by a bad one, and thus their difference increases. Now, when $D$ increases, investors' required promised repayment also does and hence the absolute values of debt mispricings $M_{b}(X, D, p)$ and $-M_{g}(X, D, p)$ also increase. Finally, when $X$ increases banks have more collateral to satisfy their debt promises which reduces the absolute values of debt mispricings. 


\subsection{Rescuing as a signal of quality}

Suppose investors ask promised repayment schemes $R_{1}, R_{0}$ in order to supply the funds that rescuing and not rescuing banks need, respectively. I say that banks of type $j$ have more incentives to rescue than banks of type $j^{\prime} \neq j$ if in case the latter find it weakly optimal to rescue then the former find it strictly optimal.

The fact that banks' types (and the asymmetric information about them) affect the quality of the assets held both by the banks and their vehicles, generates two opposite forces driving which of the bank types has more incentives to rescue. On the one hand, if banks only differed on the quality of their vehicles' assets, good banks would have more incentives to rescue their (better) vehicles than bad banks. On the other hand, if banks only differed on the quality of their on-balance sheet assets, then bad banks would have more incentives to rescue because of the risk-shifting motives that arise among weak institutions financed with overpriced debt. The following lemma states the non trivial result that when $Y_{g} \underset{M L R}{\succ} Y_{b}$ the first force dominates:

Lemma 2 For any promised repayment schemes $R_{1}, R_{0}$ with $R_{1, F}<\infty$ asked by investors for the refinancing of rescuing and not rescuing banks, respectively, good banks have more incentives to rescue than bad banks.

Because of this "single-crossing" type of result, the rescue decision $(a=1)$ is going to be systematically interpreted by investors as a signal of quality. A first implication is:

Corollary 1 If the aggregate financial sector is solvent, i.e. if

$$
(Z+1)\left(\alpha E\left[Y_{g}\right]+(1-\alpha) E\left[Y_{b}\right]\right)>D_{B}+D_{S},
$$

in equilibrium all good banks decide to rescue and the rescues can be financed.

The intuition for this result is that, on the one hand, good banks have fundamental motives to rescue their solvent but illiquid vehicles, and, on the other, this decision is also interpreted as a good signal by debt investors. Hence, good banks have all the reasons to rescue their vehicles and in equilibrium they do so. In addition, when the aggregate financial sector is solvent and, irrespectively of bad banks' rescue decisions, there is enough collateral to back both the refinancing of banks and the financing of rescues. 


\subsection{Equilibrium characterization}

Let us find the equilibrium of the model. Let us start with the case of a financial sector that is solvent on the aggregate. Then, in equilibrium all good banks decide to rescue and rescues are financed. Bayesian compatibility on investors' beliefs imposes:

$$
p_{1} \geq \alpha \text { and } p_{0}=0 .^{21}
$$

If $p_{1}=1$, the equilibrium is separating: good banks rescue and bad banks do not. If $p_{1} \in(\alpha, 1)$, it is semiseparating: good banks and some bad banks rescue, and others do not. Finally, if $p_{1}=\alpha$, it is pooling: all banks rescue.

Let us first analyze when a semiseparating equilibrium exists. Such an equilibrium is characterized by investors' beliefs $p_{1} \in(\alpha, 1)$ and $p_{0}=0$, investors' required repayments $R_{1, F}<\infty$ and $R_{0}$, such that investors' participation constraints and banks incentive compatibility constraints are satisfied: ${ }^{22}$

$$
\begin{aligned}
R_{1, F} & =R\left(Z+1, D_{B}+D_{S}, p_{1}\right), \\
R_{0} & =R\left(Z, D_{B}, 0\right) \\
\int_{0}^{\infty}\left((Z+1) y-R_{1, F}\right)^{+} f_{b}(y) d y & =\int_{0}^{\infty}\left(Z y-R_{0}\right)^{+} f_{b}(y) d y \\
\int_{0}^{\infty}\left((Z+1) y-R_{1, F}\right)^{+} f_{g}(y) d y & \geq \int_{0}^{\infty}\left(Z y-R_{0}\right)^{+} f_{g}(y) d y .
\end{aligned}
$$

$\left(P C_{1}\right)$ states that $R_{1, F}$ is such that investors' break even when they supply $D_{B}+D_{S}$ units of funds to rescuing banks that hold $Z+1$ units of assets with expected quality $p_{1}$. $\left(P C_{0}\right)$ is analogous. In a semiseparating equilibrium bad banks are indifferent between rescuing or not. According to this, $\left(I C_{b}\right)$ states that the expected net worth of a bad bank that rescues (LHS) is equal to the expected net worth of a bad bank that does not rescue (RHS). Finally, $\left(I C_{g}\right)$ states that good banks expected net worth is weakly higher if they rescue.

The indifference condition in $\left(I C_{b}\right)$ and $R_{1, F}<\infty$ imply that $R_{0}<\infty$ and banks that do not rescue obtain the required funds. In addition, Lemma 2 states that $\left(I C_{g}\right)$ is redundant

\footnotetext{
${ }^{21}$ Strictly speaking, if the equilibrium is pooling with rescue, $p_{0}$ is not pinned-down by Bayesian compatibility. In this case Proposition 2 and condition D1 imply that $p_{0}=0$.

${ }^{22}$ Let us highlight that since $R_{1, F}<\infty$ the value of $R_{1, N F}$ is irrelevant.
} 
given $\left(I C_{b}\right)$. Now, substituting $\left(P C_{1}\right)$ and $\left(P C_{0}\right)$ in $\left(I C_{b}\right)$ and using equation $(8)$ in Lemma 1 , the equilibrium conditions collapse into a single equation in $p_{1}$ :

$$
(Z+1) E\left[Y_{b}\right]-D_{B}-D_{S}+M_{b}\left(Z+1, D_{B}+D_{S}, p_{1}\right)=Z E\left[Y_{b}\right]-D_{B}+M_{b}\left(Z, D_{B}, 0\right) .
$$

Using that $M_{b}\left(Z, D_{B}, 0\right)=0$ since $R\left(Z, D_{B}, 0\right)=R_{0}<\infty$ and simplifying the equality above we obtain:

$$
M_{b}\left(Z+1, D_{B}+D_{S}, p_{1}\right)=D_{S}-E\left[Y_{b}\right]
$$

A semiseparating equilibrium exists if this equation has a solution with $p_{1} \in(\alpha, 1)$.

Equation (9) has a direct economic interpretation. The RHS is the (fundamental) cost a bad bank would incur if rescuing its vehicle under perfect information. The LHS contains the overpricing benefits a bad bank obtains from refinancing its maturing debt and financing the rescue in the same pool as the good banks. When the fundamental costs and the debt overpricing benefits of the rescue are equalized, the bad bank is indifferent between rescuing or not.

To further understand the impact of the rescue decision on a bad bank, the debt overpricing benefits that it enjoys when rescuing can be split into two components: First, there is the debt overpricing benefit of the refinancing of its original balance sheet which is

$$
M_{b}\left(Z, D_{B}, p_{1}\right)
$$

Second, there is the incremental benefit of funding the rescue with overpriced debt, which can residually be computed as

$$
M_{b}\left(Z+1, D_{B}+D_{S}, p_{1}\right)-M_{b}\left(Z, D_{B}, p_{1}\right)
$$

I now introduce the baseline parameterization of the model that I will use to illustrate the results: Assets of type $j$ follow a lognormal distribution with mean $\mu_{j}$, where $\mu_{g}=0.1, \mu_{b}=$ -0.15 , and variance $\sigma=0.25$. These numbers imply $E\left[Y_{g}\right]=1.14$ and $E\left[Y_{g}\right]=0.89$, so that the negative shock reduces by $22 \%$ the expected payoff of affected assets. The fraction of good types is $\alpha=.5$. The balance-sheet parameters are: $Z=2, D_{B}=1.53$ and $D_{S}=1.06$, which imply that the ratio of debt to market value of assets is $75 \%$ for banks and $105 \%$ for vehicles. 


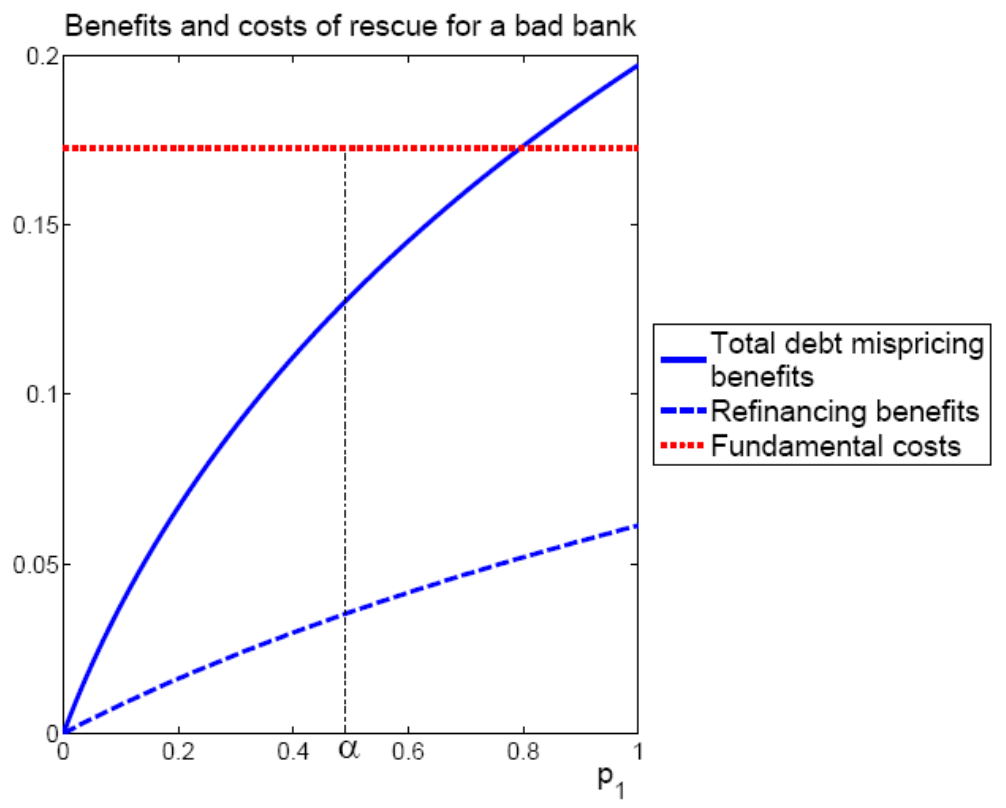

Figure 2: A bad bank's benefits and costs of a rescue as a function of the belief $p_{1}$ on the quality of a rescuing bank

Figure 2 plots the effect of investors' belief $p_{1}$ on the total debt overpricing benefits (and its two components) and compares them with the fundamental cost of the rescue. When $p_{1}=0$ the bad bank's debt is properly priced. Since the fundamental cost of the rescue for a bad bank is positive, the costs outweigh the debt overpricing benefits and the bad bank's expected net worth is lower if it rescues. As $p_{1}$ increases, a bad bank that rescues enjoys higher debt overpricing benefits both in the refinancing of its original balance sheet and in the funding of the rescue, and thus the total overpricing benefits also increase. When the curves describing the debt overpricing benefits and fundamental costs of a rescue for a bad bank intersect the bad bank is indifferent between rescuing or not. For higher investors' belief $p_{1}$ it finds it optimal to rescue. If the curves intersect in a point $p_{1} \in(\alpha, 1)$ the economy has a semiseparating equilibrium. Let $\phi$ denote the fraction of bad banks that rescue. After determining $p_{1}$, this fraction can be recursively computed out of the Bayesian compatibility of beliefs:

$$
p_{1}=\frac{\alpha}{\alpha+(1-\alpha) \phi} \Leftrightarrow \phi=\frac{\alpha\left(1-p_{1}\right)}{(1-\alpha) p_{1}} \in(0,1) .
$$

If the intersection point $p_{1}$ tends to 1 the semiseparating equilibrium approaches a sep- 
arating one. When, on the other hand, $p_{1}$ tends to $\alpha$ the equilibrium tends to a pooling one. These "limiting" equilibria extend naturally to the case in which the curves curves do not intersect in the interval $(\alpha, 1)$. The complete characterization of equilibria is given in the following proposition:

Proposition 1 If the aggregate financial sector is solvent, the equilibrium is unique, all banks are able to refinance their debt and rescues are financed. The equilibrium is:

1. Separating if and only if

$$
M_{b}\left(Z+1, D_{B}+D_{S}, 1\right) \leq D_{S}-E\left[Y_{b}\right]
$$

2. Semiseparating if and only if there exists $p \in(\alpha, 1)$ such that

$$
M_{b}\left(Z+1, D_{B}+D_{S}, p\right)=D_{S}-E\left[Y_{b}\right]
$$

in which case the fraction of bad banks that rescue their vehicles is $\phi=\frac{\alpha(1-p)}{(1-\alpha) p} \in(0,1)$.

3. Pooling if and only if

$$
M_{b}\left(Z+1, D_{B}+D_{S}, \alpha\right) \geq D_{S}-E\left[Y_{b}\right]
$$

Let us now find the equilibrium when the aggregate financial sector is insolvent. Using Assumptions 3 and 4 it is easy to realize that

$$
(Z+1)\left(\alpha E\left[Y_{g}\right]+(1-\alpha) E\left[Y_{b}\right]\right) \leq D_{B}+D_{S} \Rightarrow Z E\left[Y_{b}\right]<D_{B}
$$

and bad banks are fundamentally insolvent. ${ }^{23}$ Since a bad bank that reveals its type is not able to refinance its debt and fails at $t=0$, bad banks will always find optimal to pool with

\footnotetext{
${ }^{23}$ Indeed, if
}

$$
(Z+1)\left(\alpha E\left[Y_{g}\right]+(1-\alpha) E\left[Y_{b}\right]\right)<D_{B}+D_{S},
$$

Assumption 3 implies that

$$
(Z+1)\left(\alpha E\left[Y_{g}\right]+(1-\alpha) E\left[Y_{b}\right]\right)<D_{B}+E\left[Y_{g}\right]
$$

which can be written as

$$
[Z \alpha-(1-\alpha)]\left(E\left[Y_{g}\right]-E\left[Y_{b}\right]\right)<D_{B}-Z E\left[Y_{b}\right] .
$$

Now, Assumption 4 states that $Z \alpha-(1-\alpha) \geq 0$ and hence $D_{B}-Z E\left[Y_{b}\right]>0$. 
good banks in their rescue decision. Taking into account that investors refuse to finance a rescue intended by a bank perceived as average, we can obtain the following characterization of equilibria:

Proposition 2 If the aggregate financial sector is insolvent, there is multiplicity of equilibria. For all $\phi \in(0,1]$, a fraction $\phi$ of good banks and a fraction $\phi$ of bad banks deciding to rescue constitutes an equilibrium, and all equilibria are of this form. In all equilibria, all banks are able to refinance their debt but rescues are not financed. Finally, the expected payoff for each agent is constant in all the equilibria.

The reason why multiplicity of equilibria arises is that if investors' beliefs are $p_{1}=p_{0}=\alpha$, then they do not finance rescues and hence banks are indifferent between rescuing or not which is Bayesian compatible with investors' beliefs. In order to make notation easier, out of these essentially equivalent equilibria, I choose the pooling one in which all banks try to rescue.

Equilibrium regions Since the mispricing of the debt banks and vehicles have to refinance is the key force driving banks' decisions, it is convenient to look at equilibrium regions in the space of debt pairs $\left(D_{S}, D_{B}\right)$ that satisfy Assumptions 1, 2, and 3 which I call the admissible debt space $\mathcal{A} .^{24}$ Using the equilibrium characterization in Proposition 1, and the properties of the debt mispricing in Lemma 1 it can be proved that:

Proposition 3 The fraction $\phi\left(D_{S}, D_{B}\right)$ of bad banks that rescue their vehicles in equilibrium is decreasing in $D_{S}$ and increasing in $D_{B}$. The monotonicity is strict if $\phi\left(D_{S}, D_{B}\right) \in(0,1)$. In addition, $\phi(\mathcal{A})=[0,1]$.

The different types of equilibrium in the admissible debt space are illustrated in Figure 3. When $D_{B}$ increases bad banks obtain more debt overpricing benefits when they rescue their vehicles and the fraction of them that do so in equilibrium increases. The economy

\footnotetext{
${ }^{24}$ In terms of the other exogenous parameters of the model the admissible debt space is given by the rectangle:

$$
\mathcal{A}=\left[\alpha E\left[Y_{g}\right]+(1-\alpha) E\left[Y_{b}\right], E\left[Y_{g}\right]\right) \times\left[0, Z\left(\alpha E\left[Y_{g}\right]+(1-\alpha) E\left[Y_{b}\right]\right)\right)
$$
}




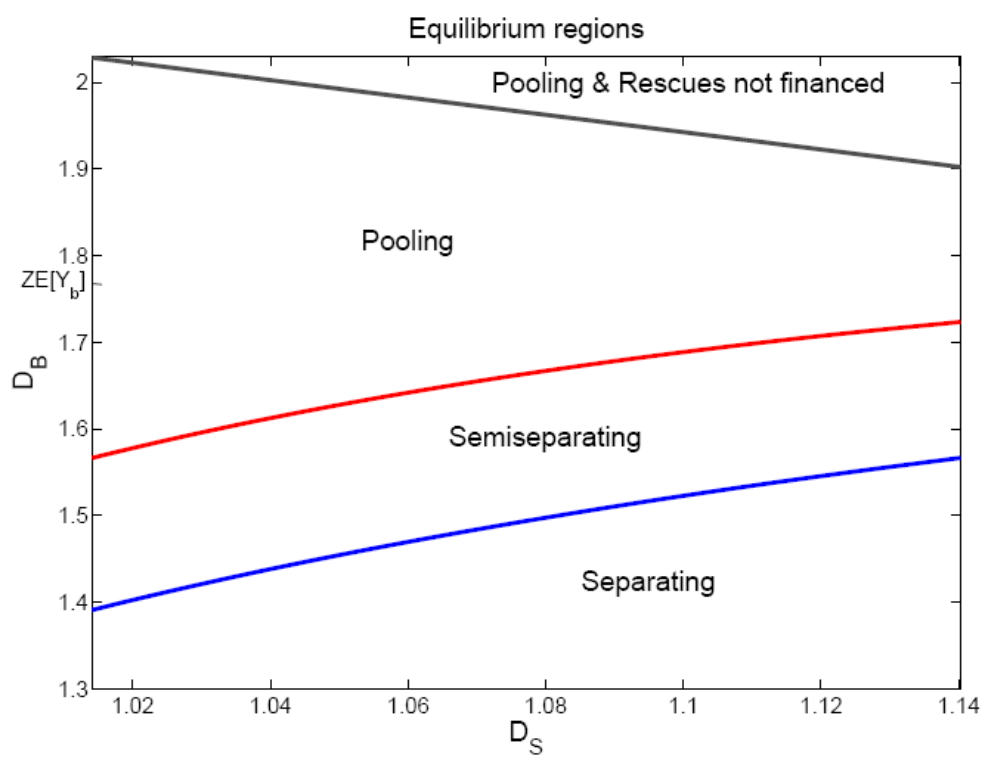

Figure 3: Equilibrium regions in the admissible debt space

moves from a separating equilibrium with no bad banks rescuing, to a semiseparating one in which some bad banks rescue, and then to a pooling equilibrium in which all banks rescue. The economy enters the pooling region significantly below the threshold $D_{B}=Z E\left[Y_{b}\right]$ over which bad banks become fundamentally insolvent.

For even higher values of $D_{B}$ the financial sector enters into the aggregate insolvency region and investors refuse to provide the additional funds needed in order to conclude the rescues. In the aggregate insolvency frontier this refusal leads to a discrete increase on the expected net worth of both types of banks. When on the other hand $D_{S}$ increases, the fundamental cost of the rescue increases faster than bad banks' debt overpricing benefits and fewer of them rescue in equilibrium. The economy may exit the pooling equilibrium region and enter into the semiseparating one. For $D_{B}$ high it can happen that as $D_{V}$ increases the financial sector becomes insolvent in the aggregate and investors refuse to finance rescues.

Effect of the severity of the negative shock I now analyze the effect of the severity of the negative shock to the quality of the assets of bad banks on the fraction of them that rescue their vehicles. In order to do so let us parameterize the random return of the bad bank assets by $Y_{b}(\tau)$ where $\tau \in[0,1]$ ranks them from best $(\tau=0)$ to worst $(\tau=1)$ in the 


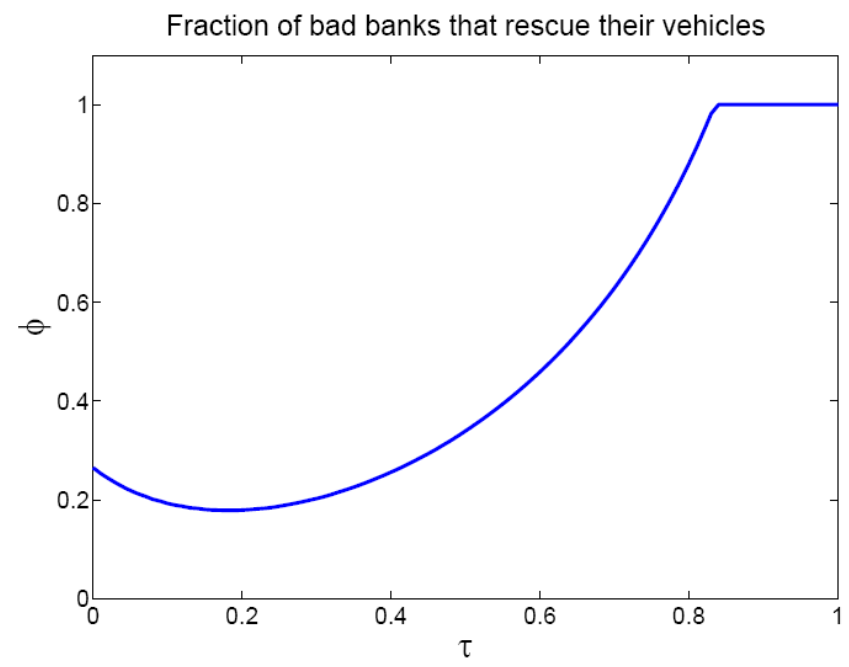

Figure 4: Fraction of bad banks that rescue as a function of severity of negative shock

sense of MLR property. Specifically, assume:

$$
Y_{g} \underset{M L R}{\succ} Y_{b}(0), Y_{b}(\tau) \underset{M L R}{\succ} Y_{b}\left(\tau^{\prime}\right) \text { if } \tau^{\prime}>\tau \text { and } Z E\left[Y_{b}(1)\right]=D_{B}
$$

so that, in particular, bad banks are just fundamentally insolvent for $\tau=1$.

Looking at the generic condition (13) that determines the trade-off that bad banks face on their rescue decision, two effects from an increase in severity $\tau$ arise: (i) the quality difference between good and bad assets increases, which increases mispricing and the debt overpricing benefits of a rescue for a bad bank; (ii) the expected value of the assets of a bad vehicle falls and consequently the fundamental cost of the rescue increases. In general, these two opposing forces produce ambiguity with respect to the impact of $\tau$ on the fraction of bad banks that rescue $\phi(\tau)$. This is illustrated in Figure 4 assuming the mean of the lognormal distribution of the bad asset is linearly decreasing in $\tau .{ }^{25}$ Despite this, I can prove that:

Proposition 4 When the severity $\tau$ of the negative shock is sufficiently high then in equilibrium all banks rescue.

\footnotetext{
${ }^{25} \mathrm{I}$ choose $\mu_{b}(\tau)=\mu_{b}^{\max }-\tau\left(\mu_{b}^{\max }-\mu_{b}^{\min }\right)$, with $\mu_{b}^{\max }=-0.05, \mu_{b}^{\min }=-0.3$. Hence, the baseline value of $\mu_{b}$ is included in the interval $\left[\mu_{b}^{\max }, \mu_{b}^{\min }\right]$. The rest of the parameters have their baseline values which were choosen so that $D_{B}=Z E\left[Y_{b}(1)\right]$ and $D_{S}=\alpha E\left[Y_{g}\right]+(1-\alpha) E\left[Y_{b}(0)\right]$.
} 


\section{Welfare effects of a ban on vehicle rescues}

The rescue of a vehicle avoids its failure. Since there are no costs associated to failure, a rescue amounts to a pure redistribution of wealth between the vehicle debtholders and the shareholders of the sponsor bank (the banker) ${ }^{26}$ In this section I analyze the distributional welfare effects of a ban on vehicle rescues that, a fortiori, deters also banks from the possibility to signal their types.

If banks are not allowed to rescue their vehicles, these fail at $t=0$ and vehicles debtholders take ownership of vehicles assets. The expected welfare of vehicles debtholders is thus:

$$
\alpha E\left[Y_{g}\right]+(1-\alpha) E\left[Y_{b}\right]<D_{S} .
$$

Since after a ban banks are pooled when refinancing their $D_{B}$ units of debt at $t=0$, the expected net worth of a bank of type $j$ is:

$$
\Pi_{j}\left(Z, D_{B}, \alpha\right)=Z E\left[Y_{j}\right]-D_{B}+M_{j}\left(D_{B}, Z, \alpha\right),
$$

Comparing these welfare expressions to their analogous in the no ban economy, which depend on the endogenous fraction $\phi$ of bad banks that rescue their vehicles, it is possible to prove the following result:

Proposition 5 There exists $D_{B}^{\prime}<Z E\left[Y_{b}\right]$ and a continuous and decreasing function $\mathcal{F}\left(D_{S}\right)$ with $\mathcal{F}\left(D_{S}\right)>D_{B}^{\prime}$ such that the effects of introducing a ban when the aggregate financial sector is solvent are the following:

1. The expected welfare of vehicles debtholders increases if and only if $D_{B} \leq D_{B}^{\prime}$.

2. The aggregate expected net worth of banks increases if and only if $D_{B} \geq D_{B}^{\prime}$.

3. The expected net worth of bad banks always strictly increases.

4. The expected net worth of good banks increases if and only $D_{B} \geq \mathcal{F}\left(D_{S}\right)$.

\footnotetext{
${ }^{26}$ The welfare analysis gets simplified taking into account that in equilibrium banks are able to refinance their debt at $t=0$ regardless of the introduction or not of the ban. As a consequence, the original bank debtholders are always fully repaid (and the new debtholders break-even in expectation).
} 
In addition, when $D_{B}=D_{B}^{\prime}$ the equilibrium is semiseparating and if $D_{B}=\mathcal{F}\left(D_{S}\right)$ the aggregate financial sector is solvent.

Let us give some intuitions for these results. In the no ban economy the expected welfare of vehicles debtholders is:

$$
(\alpha+(1-\alpha) \phi) D_{S}+(1-\alpha)(1-\phi) E\left[Y_{b}\right]
$$

Comparing to their welfare in the ban economy in (16) we deduce that the ban trivially decreases vehicles debtholders welfare when $\phi=1$ but, interestingly, the ban increases their welfare when $\phi=0$. The reason is that in a separating equilibrium the fundamentally solvent vehicles are rescued and vehicles debtholders take ownership only of the assets of the failing vehicles which are bad. Generally, whether or not these agents benefit from the ban will depend on the fraction $\alpha+(1-\alpha) \phi$ of them that are rescued in the no ban economy and on the full repayment $D_{S}$ they receive in case of rescue. The proposition states that when $D_{B}$ is below a threshold $D_{B}^{\prime}$ the economy is "closer" to the separating case than to the pooling one and these agents benefit from a ban. ${ }^{27}$

The ban always increases the expected net worth of bad banks since it allows them to pool the refinancing of their debt without the need to incur the costly rescue of their vehicles. Interestingly also, despite the fact that good vehicles are fundamentally solvent, the effect of the ban on the expected net worth of good banks is also ambiguous. Using expressions in (8) and (17), the expected net worth of good banks increases with the ban if

$$
M_{g}\left(Z, D_{B}, \alpha\right)-M_{g}\left(Z+1, D_{B}+D_{S}, p\right) \geq E\left[Y_{g}\right]-D_{S}, \text { with } p=\frac{\alpha}{\alpha+(1-\alpha) \phi}
$$

The LHS accounts for the reduction in good banks' debt underpricing due to the ban and can be interpreted as the (signed) benefits of the ban for these agents. ${ }^{28}$ In the RHS there is the fundamental benefit of the rescue for good banks and can be interpreted as the cost of the ban for them. Since $-M_{g}\left(Z+1, D_{B}+D_{S}, p\right)$ is decreasing in $p$ and $p$ is decreasing in $\phi$, inequality (19) could be satisfied for $\phi$ high. The proposition states that this is the case

\footnotetext{
${ }^{27}$ Let us highlight that this threshold is independent of the value of $D_{S}$ even though the latter affects both $\phi$ and the repayment debtholders of rescued vehicles obtain. For details see the proof of Proposition 5.

${ }^{28} \mathrm{It}$ is easy to prove that the term is positive for $\phi=1 \Leftrightarrow p=\alpha$. It is trivially negative for $\phi=0 \Leftrightarrow p=1$.
} 


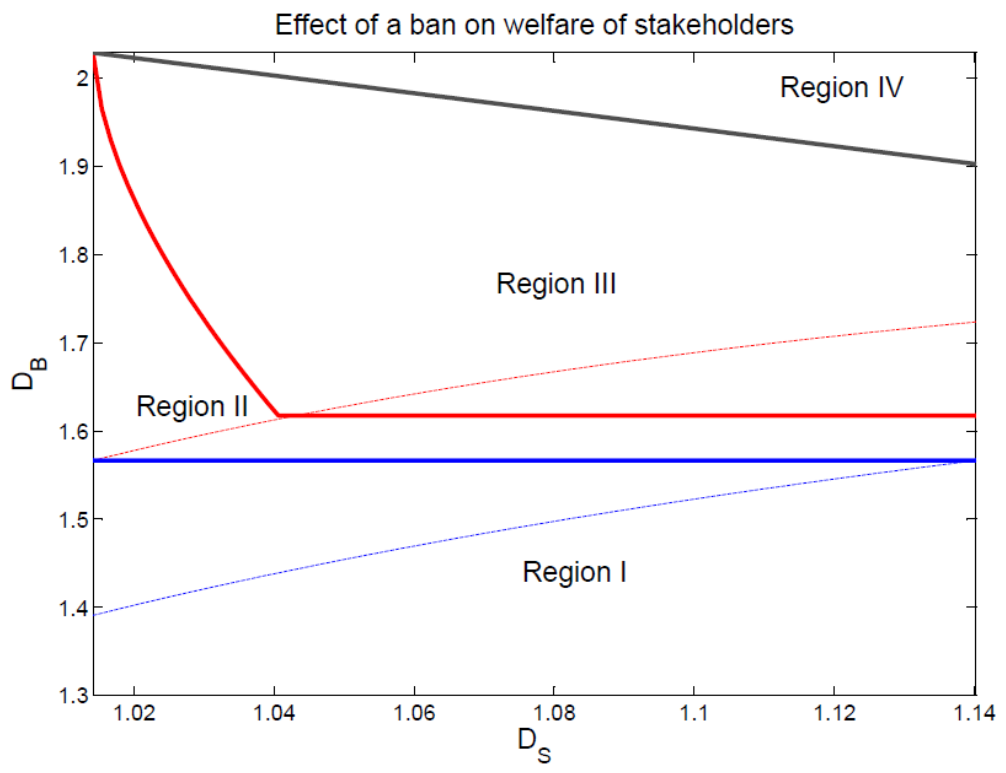

Figure 5: Effect of a ban on the welfare of different stakeholders

when $D_{B}$ is above the threshold $\mathcal{F}\left(D_{S}\right)$. When $D_{S}$ increases the fundamental benefit of a rescue for a good bank decreases while the equilibrium debt underpricing costs are increased. In order to restablish equality in (19), $D_{B}$ has to decrease which explains why the threshold $\mathcal{F}\left(D_{S}\right)$ is decreasing in $D_{S}$. (See the proof of the proposition for details).

The results in Proposition 5 are illustrated in Figure 5 where I show the different regions in which the admissible debt space is partitioned with respect to the effect of the ban for the different stakeholders. (In order to give a reference on the type of equilibrium in every region the pooling and separating equilibrium frontiers are plot with dotted lines). These welfare effects are summarized in Table 1. Bad banks benefit from a ban in all regions except IV where the aggregate financial sector is insolvent and investors decline to finance the rescues even with no ban on them. Only in region I, which corresponds to $D_{B} \leq D_{B}^{\prime}$, vehicles debtholders benefit from the ban. Equivalently, only in this region the expected net worth of aggregate banks decreases with the ban. In region II, where $D_{B}^{\prime} \leq D_{B} \leq \mathcal{F}\left(D_{S}\right)$, more bad banks rescue in equilibrium and the aggregate banking system benefits from a ban while good banks do not. Let us highlight that in this region there are pooling equilibria for $D_{S}$ close to its lower bound. In region III, with $D_{B}$ even higher, bad banks are in a more 
distressed situation and even more of them (if not all) rescue in equilibrium. Both effects increase good banks' dilution costs and also these types benefit from the ban. Finally if $D_{B}$ keeps on increasing, the financial sector enters region IV where the ban has no effect.

$\begin{array}{lcccc} & \text { Region I } & \text { Region II } & \text { Region III } & \text { Region IV } \\ \text { Vehicles' debtholders } & + & - & - & = \\ \text { Aggregate banks } & - & + & + & = \\ \text { Good banks } & - & - & + & = \\ \text { Bad banks } & + & + & + & =\end{array}$

Table 1: Summary of welfare effects of ban in the different regions

\section{$5 \quad$ Extensions and discussion}

In this section I extend the model in several dimensions and analyze robustness. Section 5.1 analyzes the effect of allowing rescues to dilute banks' preexisting debt. I find that this can lead to the collapse of the whole banking system after banks rescue their vehicles. Section 5.2 extends the model to include a second sponsored vehicle by each bank whose debt is guaranteed. I show that these explicit guarantees increase the incentives bad banks have to rescue their unguaranteed vehicles. Section 5.3 describes a variation of the model that accounts for an alternative signaling theory that may explain voluntary support and compares its predictions to those of the baseline model. Section 5.4 analyzes the robustness of the model to changes in the main assumptions.

\subsection{Seniority of preexisting bank debt}

In the model preexisting bank debt is senior to debt raised for the financing of the rescue. As a result, the rescue of a vehicle cannot dilute bank debtholders and, when the aggregate financial sector is insolvent, banks try to rescue their vehicles but investors refuse to provide them the additional required funding. However, in order to rescue their SIVs, European banks relied in the dollar denominated lending that the ECB was able to provide them after entering into an emergency swap currency line with the Federal Reserve in December 2007. Since central bank lending is secured, the lending from the ECB might have diluted the claims of other unsecured debtholders. 
In order to extend the model to account for the possibility of diluting banks' preexisting debt, let us assume that a rescue is the following bi-party deal: the vehicle's asset is transferred to the bank and its debt is swapped into bank debt with the same principal as the vehicle's debt and the same maturity as the bank's original debt. A rescuing bank then tries to raise $D_{B}+D_{S}$ units of funds to repay its debtholders (including the new debtholders coming from the debt swap). If investors are not willing to supply these funds the bank fails and its $Z+1$ units of assets are distributed pari passu among all its debtholders. The key difference with respect to the baseline model is that in this setup the intended rescues are always feasible, even if banks are unable to refinance their overall new debt soon after. ${ }^{29}$

Specifically, in the region where the aggregate financial sector is insolvent, banks are (unconditionally) insolvent after completing their rescues and investors refuse to refinance them, so the whole banking system collapses at $t=0$. In other words, the run on SIVs propagates to a run on banks due to their rescue decisions. This has an important policy implication: to the extent that central banks provide secured lending in crisis times they should be very attentive to the use banks give to borrowed funds. Lack of doing so may be instrumental to the contagion of distress from the shadow banking system to the regulated banking system.

\subsection{Banks with guaranteed vehicles}

In the run-up to the 2007 financial crisis banks sponsored several types of off-balance sheet ABCP conduits that differed on the extent of support guarantees granted to them. In order to analyze how the presence of explicitly guaranteed vehicles affects banks' incentives to rescue their unguaranteed vehicles, I extend the model and assume that every bank sponsors a second guaranteed vehicle. At $t=0$ this vehicle has $\bar{Z}>0$ units of the asset of quality $j$, where $j$ is the type of its sponsor bank, and $\bar{Z} D_{S}$ units of guaranteed debt that has to be refinanced. ${ }^{30}$ The guarantee implies that if investors are not willing to refinance the vehicle the sponsor bank is contractually obliged to rescue it.

\footnotetext{
${ }^{29}$ Formally, at the refinancing stage $R_{1}$ consists of a single promised repayment in order to supply $D_{B}+D_{S}$ units of funds instead of a contingent pair of promised repayments $\left(R_{1, F}, R_{1, N F}\right)$. It can be proved that, since banks are solvent in the aggregate whereas vehicles are not, vehicles' debtholders would accept the exchange of their debt for bank debt even if they are not fully repaid by the banks after the rescue.

${ }^{30}$ So $\bar{Z}$ is the relative size of the guaranteed vehicles with respect to the unguaranteed ones.
} 
At $t=0$ both vehicles are unable to refinance their debt. Each bank rescues its guaranteed vehicle and has to decide whether to rescue the unguaranteed one. If a bank does not rescue this vehicle, it asks investors for the financing of $D_{B}+\bar{Z} D_{S}$ units of debt backed by $Z+\bar{Z}$ units of assets, whereas if it does, the debt to finance increases to $D_{B}+(\bar{Z}+1) D_{S}$ and is backed by $Z+\bar{Z}+1$ units of assets. These are the only differences with respect to the baseline model. Hence, in equilibrium all good banks rescue their unguaranteed vehicle and the benefit vs cost trade-off that bad banks face in their rescue decision (previously reflected in (13)) becomes:

$$
M_{b}\left(D_{B}+(\bar{Z}+1) D_{S}, Z+\bar{Z}+1, p\right)=D_{S}-E\left[Y_{b}\right]
$$

From here we have that:

Proposition 6 Let $\phi(\bar{Z})$ be the fraction of bad banks that rescue their unguaranteed vehicles in equilibrium when the size of the guranteed vehicles is $\bar{Z} \geq 0$. If $0<\phi(\bar{Z})<1$ then $\phi(\bar{Z})$ is strictly increasing in $\bar{Z}$.

When banks are contractually forced to bring some vehicles back on balance sheet, the degree of asymmetric information in the banking system increases and bad banks value more preserving their private information (i.e. the debt overpricing benefits of a rescue in the LHS of (20) increase). As a consequence, in equilibrium the fraction of bad banks that rescue the unguaranteed vehicle increases.

This result identifies a novel complementarity between contractual and voluntary support of sponsored vehicles and gives yet another reason that may have pushed banks to the rescue of their SIVs. From an ex-ante perspective, the contractual obligation to support some vehicles serves to commit to (voluntarily) support other similar vehicles. To the extent that recourse is appreciated by vehicles' investors and contractual guarantees are costly, banks may have exploited this complementarity in their choice of an optimal mix of guaranteed and unguaranteed vehicles. ${ }^{31}$

\footnotetext{
${ }^{31}$ The standard argument for the value created by recourse is that it reduces moral hazard/adverse selection problems at origination (Gorton and Souleles, 2006). But recourse may be costly from a regulatory perspective. Since 2004 bank regulators in the US required sponsors to hold capital requirements against the provision of liquidity guarantees to conduits at a conversion factor of $10 \%$ relative to on-balance sheet financing. In Europe, banks that had adopted Basel II were applied a conversion factor of $20 \%$ while for those under Basel I it was 0\%.
} 


\subsection{Reputation concerns and future financing}

Regulators and rating agencies have provided yet another view on the reasons why a sponsor may voluntarily support its conduits: the sponsor's concern that "failure to provide support would damage its future access to the asset-backed securities market" (OCC, 2002, p.3) ${ }^{32}$ Capturing this explanation formally only requires a small variation in the model under which most of the economic intuition behind the results is preserved. However, I find that when rescuing is a signal directed to reduce the financing costs of future investment opportunities it is less likely that sponsors support their vehicles under stressful economic situations.

The future financing model (to be distinguished from the current refinancing baseline model) is as follows. There is a new intermediate date, $t=1 / 2$. At $t=0$ banks have $Z_{0}<Z$ units of their asset and no debt. ${ }^{33}$ At $t=1 / 2$ banks have access to a new investment opportunity: they can acquire $Z_{1 / 2}=Z-Z_{0}$ units of their asset at the cost $D_{B}$ that is financed by debt issued to investors. So if a bank invests at $t=1 / 2$ the size of its assets and outstanding debt is the same as in the current refinancing model. I assume that for good banks the investment opportunity has positive fundamental NPV:

$$
Z_{1 / 2} E\left[Y_{g}\right]>D_{B}
$$

Vehicles are as in the baseline model. Investors at $t=0$ and $t=1 / 2$ are in excess supply and competitive. When vehicles suffer a run on their debt at $t=0$ their sponsors decide whether or not to rescue them. In case they do, the debt they issue in order to finance the rescue has to be refinanced at $t=1 / 2$.

Using an analogous to Lemma 2 it can be proven that in equilibrium good banks rescue their vehicles at $t=0$ and take the investment opportunity at $t=1 / 2$. Bad banks in their rescue decision trade-off the fundamental costs of the rescue and the benefits of improving the cost of financing the future investment opportunity. If rescuing banks are perceived to be of quality $p$ bad banks' indifference condition analogous to (13) can be written as:

$$
M_{b}\left(Z+1, D_{B}+D_{S}, p\right)=D_{S}-E\left[Y_{b}\right]+\max \left(D_{B}-Z_{1 / 2} E\left[Y_{b}\right], 0\right) .
$$

The new term $\max \left(D_{B}-Z_{1 / 2} E\left[Y_{b}\right], 0\right)$ captures the fact that in case bad banks' investment

\footnotetext{
${ }^{32}$ See also FitchIBCA (1999, p. 4).

${ }^{33}$ I could allow for positive debt $D_{0}>0$ at $t=0$ which would generate a current refinancing concern in
} 


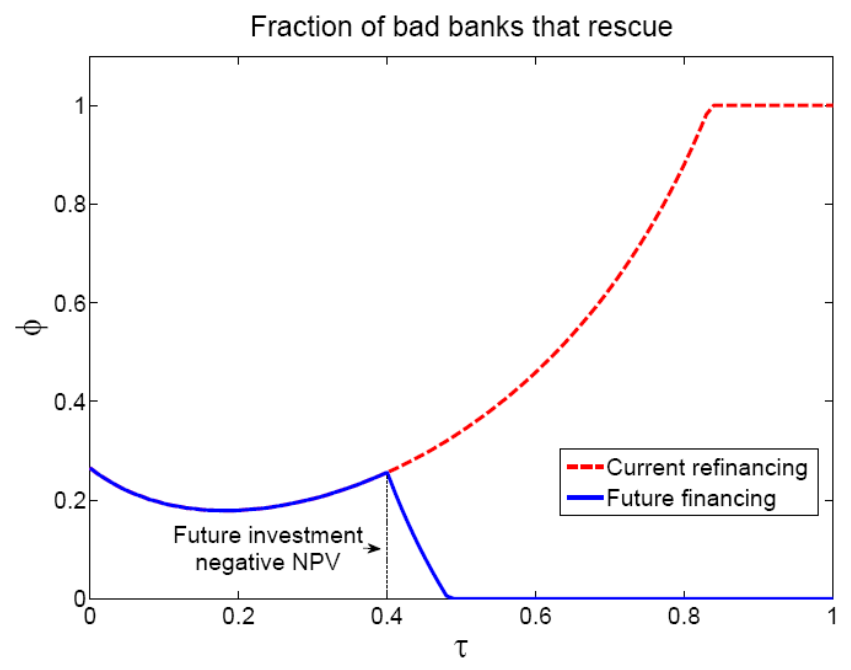

Figure 6: Fraction of bad banks that rescue as a function of severity of negative shock

opportunity at $t=1 / 2$ has negative fundamental NPV, the banks have the option not to invest. This option reduces bad banks' incentives to rescue their vehicles with respect to the baseline model. I now reconduct the exercise at the end of Section 3.4 on the effect of the severity of the negative shock on the equilibrium of the future financing model. Figure 6 shows the fraction of bad banks that rescue their vehicles in both models. ${ }^{34}$ We observe that when bad banks' investment opportunity has positive fundamental NPV, the equilibria of both models coincide. However as the severity of the shock increases and investment for bad banks has fundamental negative NPV, each equilibrium evolves in opposing directions: the future financing economy moves fast to a separating equilibrium, while the current refinancing one converges to a pooling equilibrium with rescue. This result suggests that, in the contractionary context of the end of 2007, preserving the reputation of banks' balance sheet was a more decisive factor on the rescue of SIVs than maintaining investors' confidence on the future of banks' securitization business.

banks rescue decisions. In order not to mix the two channels I assume $D_{0}=0$.

${ }^{34}$ The figure uses the following values for the new parameters of the future financing economy: $Z_{0}=0.2$ and $Z_{1 / 2}=1.72$. 


\subsection{Robustness}

In this Section I briefly comment the robustness of the model to relaxing some of the main assumptions.

Risk insensitive banks' debt The model can be extended to include a fraction of banks' debt that is risk insensitive. This insensitivity could be the result of explicit deposit insurance or of bailout expectations from debt investors. Since in this case a smaller proportion of banks' debt is sensitive to investors' expectation on the quality of the bank, the incentives for bad banks to rescue are reduced. As a result, the fraction of bad banks that rescue their vehicles in equilibrium is reduced.

Imperfect positive correlation between banks and sponsored vehicles' assets The type of a bank determines the common quality of the assets of the bank and its vehicle. While some positive correlation is necessary for the results, the assumption of perfect correlation was adopted for simplicity. More specifically, all the mechanisms in the model are preserved if $\mathrm{I}$ incorporate in the balance sheet of banks also $Z_{W}$ units of a new asset with gross return $W$ whose distribution is common knowledge (and independent from that of $Y_{j}, j=g, b$ ). This asset can be thought as a traditional banking asset, whose quality is not a concern for investors, that differs from the securitized assets of the baseline model, whose opacity generates asymmetric information. ${ }^{35}$

Fundamentally insolvent good vehicles If Assumption 3 is relaxed to allow for both types of vehicles to be fundamentally insolvent, i.e. if:

$$
E\left[Y_{b}\right]<E\left[Y_{g}\right]<D_{S}
$$

then also good banks rescuing their vehicles incur a positive fundamental cost. Since the validity of Lemma 2 does not depend on this assumption, the rescue decision is still a signal of quality. Hence, a good bank that rescues benefits from a reduction in debt underpricing

\footnotetext{
${ }^{35}$ In the extension, the perfect correlation between some of the bank assets and vehicles' would capture that banks held tranches of the securitized and distribitued assets, that banks had on balance sheet the assets of similar previously rescued vehicles, and also that they were holding pools of assets waiting to be securitized and transferred to their vehicles when the crisis erupted.
} 
costs that overweighs the fundamental costs of the rescue when these are not very important, i.e. when $D_{S}-E\left[Y_{g}\right]$ is not very high. In this case the unique equilibrium of the economy is the one characterized in Section 3.4. In contrast, if $D_{S}$ is sufficiently high the unique equilibrium of the economy would be pooling with no rescue. ${ }^{36}$

Small size of banks relative to vehicles If $Z$ is small and Assumption 4 is not satisfied there are situations in which bad banks are solvent but the aggregate economy is insolvent. In these cases there are two equilibria: the one characterized in Section 3.4 in which rescues are not financed and another one in which all good banks rescue, only a fraction of bad banks do so and rescues are financed. ${ }^{37}$ The source of multiplicity is a complementarity between bad banks' actions and investors' beliefs on these actions that arises due to the possibility that investors refuse to finance rescues when they believe many bad banks want to do so. This possibility materializes in equilibrium only when the aggregate economy is insolvent and bad banks are fundamentally solvent.

\section{Conclusions}

In this paper I develop a signaling theory that explains sponsor banks voluntary support of their SIVs at the beginning of the 2007 financial crisis. In an economy in which debt investors have imperfect information on the institutions affected by a negative shock, a bank that rescues its vehicle sends a positive signal because investors anticipate that good banks have more incentives to rescue than bad ones. As a result, in equilibrium the costs of refinancing the balance sheet of the signaling bank are reduced and good banks always find it optimal to rescue their (solvent) vehicles. In contrast, a bad bank trades off the fundamental costs of rescuing its (insolvent) vehicle with the debt overpricing benefits of keeping its own type unrevealed.

When the crisis started in August 2007 banks were highly levered and their short term

\footnotetext{
${ }^{36}$ There is an intermediate range of values of $D_{S}$ for which there is multiplicity of equilibria. These equilibria are: the equilibrium in which all good banks rescue their vehicles, a pooling equilibrium with no rescue, and an unstable semiseparating equilibrium in which only a fraction of good banks rescue. The net worth of both types of banks is maximized in the pooling equilibrium with no rescue and a ban on rescues would be a way to coordinate banks on the outcome that is best for them.

${ }^{37}$ The fraction of bad banks that rescue in this equilibrium is determined by equation (13).
} 
debt required regular refinancing in wholesale markets. In addition, agents' downward updating of the value of subprime associated assets was very severe. In circumstances like these, my model predicts a pooling equilibrium with rescue as the one we observed in reality. I also show that having vehicles with explicit support guarantees would further push in favor of the emergence of the pooling equilibrium regarding the rescue of the unguaranteed vehicles.

Regulators have manifested concern about the cost of these actions for the banking system and in most jurisdictions voluntary support will be banned in the future. In the context of my model I show that if the aggregate financial sector is close to insolvency the net worth of all banks would increase with a ban on rescues that prevents them from engaging in this form of costly signaling.

The ECB provided the dollar funding European banks needed to rescue their SIVs and hence, since central bank lending is secured, the funding for these rescues was de facto senior to the banks' preexisting debt. I show that when this is the case, vehicles inability to refinance their debt may propagate to banks due to their rescue decisions. The result shows that central banks may play an instrumental role for the contagion of distress from the shadow banking system to the regulated banking system and calls for these institutions to closely monitor banks' use of the funds they provide during liquidity crises.

Finally, some regulators and rating agencies argued that voluntary support was a response to sponsors fear to lose access to the securitization business in the future (if they had let their conduits fail). A minimal variation in the model allows me to capture this alternative reputation theory. However, I show that this concern for future financing is weaker when economic prospects are poorer, which suggests that this alternative reputational story is less plausible as an explanation of the events observed in the past financial crisis. 


\section{Appendix}

\section{A The SIV industry: rise and demise}

Since the mid 1980s, banks have been sponsoring ABCP conduits for the off-balance sheet funding of a varied range of assets. The main source of financing of these conduits is commercial paper (CP) that, as opposed to corporate CP, is secured by the conduits' assets and also enjoys from the "bankruptcy remoteness" of the conduits. By June 2007 these conduits constituted an important part of the shadow banking system with outstanding ABCP amounting to $\$ 1.3$ trillion, $\$ 903$ billion of which were sponsored by banks.

There are four types of ABCP conduits (single-seller, multiseller, securities arbitrage vehicles and SIVs) that differ on the types of assets they hold, their liability structure, their governing accounting rules and, most importantly for the focus of this paper, on the contractual support guarantees from their sponsors. In order to achieve the maximum rating on the liabilities issued by their conduits and make them eligible for institutional investors such as MMMFs, sponsors extend support facilities to their conduits. These can require the sponsor to pay off the full principal of maturing ABCP in case the conduit is not able to roll it over at the market (full support) or only a fraction of it (partial support). ${ }^{38}$ SIVs were the only partially supported ABCP conduits.

SIVs engage in spread lending by investing in highly-rated long-term securities that are financed by the issuance of ABCP and medium term notes (MTN) in a typical ratio of 2:5. In order to provide some credit risk protection to their investors, SIVs also issue subordinated capital notes that constitute between $6 \%$ and $10 \%$ of total assets. SIVs operate on a marked-to-market basis and must meet strict liquidity, capitalization, leverage and concentration guidelines whose violation leads to limitations on the vehicles' operations and eventually to liquidation. The asset portfolio is typically managed by the sponsoring institution. Even though general characteristics about the portfolio (e.g.: type of assets, industry concentration) are part of the programs and are monitored by rating agencies, the specific assets held are considered by sponsors as proprietary information and not disclosed. Finally, sponsors in their role of administrators of the vehicles obtain fees that are proportional to their net profits. ${ }^{39}$

\footnotetext{
${ }^{38}$ Formally, there is a distinction between full credit support in which the sponsor has to pay off maturing ABCP in all circumstances and full liquidity support in which the sponsor has to pay it off only if the conduit's assets are not in default. In practice, liquidity support gives the same level of protection to the investors because $\mathrm{ABCP}$ investors can withdraw before assets enter into default. Preferable regulatory treatment of liquidity support has led most sponsors to use it for their fully supported conduits (see Acharya et al., 2013).

${ }^{39}$ For more institutional details on SIVs and a description of the other types of ABCP conduits see Moody's
} 
The first SIV was launched by Citibank in 1988 and at the zenith of the sector in July 2007 there were 34 SIVs with a total of $\$ 400$ billion of assets, outstanding ABCP of $\$ 97$ billion (7.5\% of the ABCP market) and MTN of $\$ 270$ billion. Banks sponsored 19 of the SIVs, that accounted for $85 \%$ of the assets managed by the sector. The largest player in the market was Citibank which sponsored seven SIVs with $101 \$$ billion of assets (25\% of the market), which constituted a 5\% of its on-balance sheet assets and $110 \%$ of its Tier 1 capital. Other important bank sponsors were HSBC (12\%) and Dresdner Bank (10\%).

When investors became nervous about the location of toxic subprime assets in August 2007, they stopped rolling over ABCP or required very high yields in order to do so. The run was more pronounced on SIVs due to the lack of full support from their sponsors (Covitz et al., 2013), and led two non-bank sponsored SIVs to default on their ABCP on August 22. ${ }^{40}$

Problems aggravated in September when Moody's downgraded and placed under negative review the ratings of several SIVs. ${ }^{41}$ On September 20, Sachsen Funding Ltd was the first SIV to be rescued. ${ }^{42}$ Fearing the potential destabilizing effect of massive fire sales from SIVs trying to obtain liquidity in order to repay ABCP at maturity, the US Treasury tried to coordinate a private bail out of the SIV sector. This government supported plan led Citigroup, JP Morgan Chase and Bank of America to propose in October the creation of the Master Liquidity Enhancement Conduit, also known as Super SIV, a conduit partially capitalized by these institutions that would buy the highest-quality assets of SIVs with liquidity needs. However, problems in attracting external investors to the Super SIV delayed its creation and, after the failure of two additional SIVs, HSBC announced the rescue of its two SIVs in November 26. Under the pressure from market commentators and participants who commonly alluded to the reputation of the sponsors, other banks followed HSBC and announced rescue plans for their sponsored SIVs in the subsequent dates. On December 14, Citigroup announced the rescue of its seven SIVs and the creation of the Super SIV was abandoned. By February 2008 most sponsoring banks had announced their intentions to rescue their vehicles. ${ }^{43}$

Investors Service (2003) or Arteta et al. (2013).

${ }^{40}$ Golden Key Ltd, sponsored by the investment manager Avendis Financial Services Ltd, and Mainsail II Ltd, sponsored by the hedge fund Solent Capital Ltd.

${ }^{41}$ At the end of July Moody's had published a Special Report with the title "SIVs: An Oasis of Calm in the Sub-prime Maelstrom". This complete change of assessment is indicative of the level of imperfect information on the sectors' exposure to subprime risk.

${ }^{42}$ The rescuer was the German landesbank LB Baden-Württemberg that had acquired with public support at the end of August the sponsor of this SIV, Sachsen LB. The latter needed the bail out due to the losses incurred as a result of the run on its supported ABCP conduits.

${ }^{43} \mathrm{IKB}$ Deutsche Industriebank was bailed out by a consortium of banks leaded by the German state owned bank KfW in August 2007 due to its exposure to Rhineland FCC, a hybrid ABCP conduit. Rhinebridge $\mathrm{Plc}$, the SIV sponsored by IKB defaulted on October 16 while IKB was merged with KfW. Hong Kong 
Although the particular details on how rescues were structured differed across banks, they all amounted to a de facto transfer of the vehicle assets on balance sheet, the full repayment of senior debtholders and the end of the operation of the SIV as a going concern. For example, HSBC rescue and restructuring plan for his sponsored SIVs considered the exchange of maturing debt by similar debt issued by a newly created and fully supported conduit to which the SIVs' assets would be transferred.

In October 2008 Moody's announced the closure of the ABCP program of Sigma Finance Corporation, putting an end to this twenty year old industry. ${ }^{44}$

\section{B Proofs}

Proof of Lemma 1 Using the definitions of $\Pi_{j}(X, D, p)$ in $(6), V_{j}(X, R)$ in (2) and $M_{j}(X, D, p)$ in (7), after some straightforward manipulation the expression in (8) is obtained.

From now on I assume $R(X, D, p)<\infty$. Using (4) and (5) and the definition of the mispricings in (7) we obtain:

$$
\begin{aligned}
& M_{b}(X, D, p)=p\left(V_{g}(X, R(X, D, p))-V_{b}(R(X . X, D, p))\right) \\
& M_{g}(X, D, p)=(1-p)\left(V_{b}(X, R(X, D, p))-V_{g}(X, R(X, D, p))\right)
\end{aligned}
$$

and from here the equality

$$
p M_{g}(X, D, p)+(1-p) M_{b}(X, D, p)=0 .
$$

For $j=g, b$, we have:

$$
\frac{\partial V_{j}(X, R)}{\partial R}=\operatorname{Pr}\left[X Y_{j} \geq R\right]=1-F_{j}\left(\frac{R}{X}\right)>0
$$

where $F_{j}(y)$ denotes the cdf of $Y_{j}$. Since $Y_{g}$ strictly first order stochastically dominates $Y_{b}$ we have that

$$
F_{b}\left(\frac{R}{X}\right)>F_{g}\left(\frac{R}{X}\right) \Leftrightarrow \frac{\partial V_{g}(X, R)}{\partial R}>\frac{\partial V_{b}(X, R)}{\partial R}
$$

based Standard Chartered Bank announced the rescue of its vehicle Whistlejacket Capital Ltd on November 2007, but the vehicle defaulted on February 2008 prior to completing its rescue. These were the only bank sponsored SIVs to default, arguably because their intended rescues arrived too late.

${ }^{44}$ The non SIV segment of the ABCP market was also severely disrupted by the financial crisis and has been declining since. The outstanding ABCP in September 2013 is $\$ 273$ billion, around $20 \%$ of its size in June 2007. 
By construction $R(X, D, p)$ satisfies:

$$
p V_{g}(X, R(X, D, p))+(1-p) V_{b}(X, R(X, D, p))=D
$$

Differentiating wrt $D$ the equation above we obtain:

$$
\left[p \frac{\partial V_{g}(X, R)}{\partial R}+(1-p) \frac{\partial V_{b}(X, R)}{\partial R}\right] \frac{\partial R}{\partial D}=1
$$

and therefore:

$$
\frac{\partial R(X, D, p)}{\partial D}=\frac{1}{p\left(1-F_{g}\left(\frac{R}{X}\right)\right)+(1-p)\left(1-F_{b}\left(\frac{R}{X}\right)\right)}>0
$$

Now, differentiating wrt $D$ in the definition of $M_{b}(X, D, p)$ in $(7)$ we get:

$$
\begin{aligned}
\frac{\partial M_{b}(X, D, p)}{\partial D} & =1-\frac{1-F_{b}\left(\frac{R}{X}\right)}{p\left(1-F_{g}\left(\frac{R}{X}\right)\right)+(1-p)\left(1-F_{b}\left(\frac{R}{X}\right)\right)} \\
& =p \frac{F_{b}\left(\frac{R}{X}\right)-F_{g}\left(\frac{R}{X}\right)}{p\left(1-F_{g}\left(\frac{R}{X}\right)\right)+(1-p)\left(1-F_{b}\left(\frac{R}{X}\right)\right)},
\end{aligned}
$$

where in the last equality we have used (26). From inequality (24) we immediately conclude that $0<\frac{\partial M_{b}(X, D, p)}{\partial D}<1$ if $p>0$. Differentiating equation (27) wrt $D$ again and using (23), (26) we obtain:

$$
\begin{gathered}
\frac{\partial^{2} M_{b}(X, D, p)}{\partial D^{2}}=\frac{1}{X} \frac{f_{b}\left(\frac{R}{X}\right)}{\left[p\left(1-F_{g}\left(\frac{R}{X}\right)\right)+(1-p)\left(1-F_{b}\left(\frac{R}{X}\right)\right)\right]^{2}}- \\
-\frac{1}{X} \frac{\left[p f_{g}\left(\frac{R}{X}\right)+(1-p) f_{b}\left(\frac{R}{X}\right)\right]\left(1-F_{b}\left(\frac{R}{X}\right)\right)}{\left[p\left(1-F_{g}\left(\frac{R}{X}\right)\right)+(1-p)\left(1-F_{b}\left(\frac{R}{X}\right)\right)\right]^{3}} .
\end{gathered}
$$

Now, $Y_{g} \underset{M L R}{\succ} Y_{b}$ implies straightforwardly that for $p>0$ and $y>0$ :

$\frac{p f_{g}(y)+(1-p) f_{b}(y)}{f_{b}(y)}<\frac{\int_{y}^{\infty}\left(p f_{g}(z)+(1-p) f_{b}(z)\right) d z}{\int_{y}^{1} f_{b}(z) d z}=\frac{p\left(1-F_{g}(y)\right)+(1-p)\left(1-F_{b}(y)\right)}{1-F_{b}(y)}$

and using this inequality in equation (28) we conclude that $\frac{\partial^{2} M_{b}(X, D, p)}{\partial D^{2}}>0$ if $p>0$. Since $M_{b}(X, D, p)$ is homogeneous of degree one in $X, D$ we have the Euler identity:

$$
X \frac{\partial M_{b}(X, D, p)}{\partial X}+D \frac{\partial M_{b}(X, D, p)}{\partial D}=M_{b}(X, D, p)
$$

and using that $\frac{\partial^{2} M_{b}(X, D, p)}{\partial D^{2}}>0$ we obtain that $\frac{\partial M_{b}(X, D, p)}{\partial X}<0$. 
Also, differentiating implicitly wrt $p$ in (25) we obtain:

$$
V_{g}(X, R)-V_{b}(X, R)+\left(p \frac{\partial V_{g}(X, R)}{\partial R}+(1-p) \frac{\partial V_{b}(X, R)}{\partial R}\right) \frac{\partial R}{\partial p}=0,
$$

and since $V_{g}(X, R)>V_{b}(X, R)$ we deduce that $\frac{\partial R(X, D, p)}{\partial p}<0$.Using the definition of $M_{b}(X, D, p)$ :

$$
\frac{\partial M_{b}(X, D, p)}{\partial p}=-\frac{\partial V_{b}}{\partial R} \frac{\partial R}{\partial p}>0 .
$$

The results for $M_{g}(X, D, p)$ are either direct consequence of those for $M_{b}(X, D, p)$ using equation (22) or their proofs are analogous.

Proof of Lemma 2 If a bad bank weakly prefers to rescue we must have that:

$$
\int\left((Z+1) y-R_{1}\right)^{+} f_{b}(y) d y \geq \int\left(Z y-R_{0}\right)^{+} f_{b}(y) d y
$$

Let us denote

$$
g(y)=\left((Z+1) y-R_{1}\right)^{+}-\left(Z y-R_{0}\right)^{+} .
$$

The function $g(y)$ is continuous and inequality (29) simply states that $\int g(y) f_{b}(y) d y \geq 0$.

For $y \geq \max \left\{\frac{R_{1}}{Z+1}, \frac{R_{0}}{Z}\right\}$ we have $g(y)=y-R_{1}+R_{0}$ and $g(y)$ is strictly positive for $y$ sufficiently high.

If $\frac{R_{1}}{Z+1} \leq \frac{R_{0}}{Z}$ then it is easy to check that $g(y)$ is always non negative, and then trivially we have that $\int g(y) f_{g}(y) d y>0$ and the good bank strictly prefers to rescue.

If, on the other hand $\frac{R_{0}}{Z}<\frac{R_{1}}{Z+1}$, then one can check that $g(y) \leq 0$ for $y \in\left(0, R_{1}-R_{0}\right]$ and $g(y)>0$ for $y>R_{1}-R_{0}$. Let us denote $y_{1}=R_{1}-R_{0}$. We can rewrite $\int g(y) f_{b}(y) d y \geq 0$ as

$$
\int_{0}^{y_{1}}-g(y) f_{b}(y) d y \leq \int_{y_{1}}^{\infty} g(y) f_{b}(y) d y .
$$

Let us now use that $Y_{g} \underset{M L R}{\succ} Y_{b}$ to obtain the following inequalities:

$$
\frac{f_{g}(y)}{f_{b}(y)}<\frac{f_{g}\left(y_{1}\right)}{f_{b}\left(y_{1}\right)}<\frac{f_{g}\left(y^{\prime}\right)}{f_{b}\left(y^{\prime}\right)} \text { for all } y<y_{1} \text { and } y^{\prime}>y_{1} \text {. }
$$

Using inequalities (30), (31) and the fact that $g(y)<0$ for $y<y_{1}$ we have the following sequence of inequalities:

$$
\begin{gathered}
\int_{0}^{y_{1}}-g(y) f_{g}(y) d y=\int_{0}^{y_{1}}-g(y) \frac{f_{g}(y)}{f_{b}(y)} f_{b}(y) d y<\int_{0}^{y_{1}}-g(y) \frac{f_{g}\left(y_{1}\right)}{f_{b}\left(y_{1}\right)} f_{b}(y) d y \leq \\
\leq \int_{y_{1}}^{\infty} g(y) \frac{f_{g}\left(y_{1}\right)}{f_{b}\left(y_{1}\right)} f_{b}(y) d y<\int_{y_{1}}^{\infty} g(y) \frac{f_{g}(y)}{f_{b}(y)} f_{b}(y) d y=\int_{y_{1}}^{\infty} g(y) f_{g}(y) d y,
\end{gathered}
$$

and comparing the extremes of the inequality we deduce that $\int_{0}^{\infty} g(y) f_{g}(y) d y>0$ and thus a good bank strictly prefers to rescue. 
Proof of Corollary 1 The first step is to prove that a pooling equilibrium with no rescue does not exist. Indeed, using Lemma 2 refinement D1 implies that investors should believe that a bank that deviates and rescues is good. But then, good banks would strictly prefer to rescue because they would not suffer mispricing losses and on top of this they would make a profit on the rescue of their vehicles since $E\left[Y_{g}\right]>D_{V}$.

Therefore in equilibrium at least a bank of type $j \in\{g, b\}$ rescues. Let us suppose that rescues are financed, i.e. $R_{1, F}^{*}<\infty$. If $j=b$ and bad banks find it weakly optimal to rescue, then Lemma 2 implies that all good banks rescue in equilibrium. If $j=g$ but not all good banks rescue then good banks would be indifferent between rescuing and not and Lemma 2 states that bad banks would find it optimal not to rescue. Therefore banks that rescue are necessarily good and in equilibrium investors would perceive them as such. But then again good banks would strictly prefer to rescue.

For future use in the proof of Proposition 2, we have so far proved wihtout any restriction on the solvency or not of the aggregate financial sector that if in equilibirum $R_{1, F}^{*}<\infty$ then all good banks rescue.

The only thing left to prove in the corollary is that $R_{1, F}^{*}<\infty$. Let us suppose on the contrary that $R_{1, F}^{*}=\infty$. Since there is some bank that rescues we must have $R_{1, N F}^{*} \geq R_{0}^{*}$. If the inequality is strict then all banks find it optimal to rescue and $p_{1}^{*}=\alpha$. Now the fact that $R_{1, F}^{*}=\infty$ and investors do not want to finance the rescue of an average bank means that the aggregate financial sector is insolvent, which is a contradiction. If on the other hand $R_{1, N F}^{*}=R_{0}^{*}$ then due to Bayesian updating we must have $p_{1}^{*}=p_{0}^{*}=\alpha$ and again $R_{1, F}^{*}=\infty$ would mean that the aggregate financial sector is insolvent.

Proof of Proposition 1 The proof that there is a semiseparating equilibrium with a fraction $\frac{\alpha\left(1-p_{1}\right)}{(1-\alpha) p_{1}}$ of bad banks rescuing their vehicles if and only if there is a solution to equation (13) with $p_{1} \in(\alpha, 1)$ has been done in the main text.

If there is a pooling equilibrium we must have that $\left(I C_{b}\right)$ is satisfied which, after substituting the participation constraints of investors can be written as:

$$
M_{b}\left(Z+1, D_{B}+D_{S}, \alpha\right) \geq D_{S}-E\left[Y_{b}\right]+M_{b}\left(Z, D_{B}, 0\right)
$$

Using that $M_{b}\left(Z, D_{B}, 0\right) \geq 0$, this inequality implies (14). The converse is easily proved taking into account that $M_{b}\left(Z, D_{B}, 0\right)>0$ if and only if $\Pi_{b}\left(Z, D_{B}, 0\right)=0$.

If there is a separating equilibrium then we find analogously that $\left(I C_{b}\right)$ can be written

$$
M_{b}\left(Z+1, D_{B}+D_{S}, 1\right) \leq D_{S}-E\left[Y_{b}\right]+M_{b}\left(Z, D_{B}, 0\right)
$$


Now, if $M_{b}\left(Z, D_{B}, 0\right)>0$ then we have that investors do not refinance not rescuing banks. Since in equilibrium rescues are financed, in particular investors refinance rescuing banks and thus bad banks would find it optimal to rescue, which is a contradiction. Therefore it has to be the case that in a separating equilibrium $M_{b}\left(Z, D_{B}, 0\right)=0$ and the inequality above becomes (12). The converse is easily proved.

Finally, since $R\left(Z+1, D_{B}+D_{V}, p_{1}\right)<\infty$ for all $p_{1} \geq \alpha$, Lemma 1 states that $M_{b}(Z+$ $\left.1, D_{B}+D_{V}, p_{1}\right)$ is strictly increasing in $p_{1}$ for all $p_{1} \geq \alpha$. This strict monotonicity implies that the conditions (12), (13) and (14) are exhaustive and mutually exclusive and thus the equilibrium exists and is unique.

Proof of Proposition 2 I have argued in the main text that if the aggregate financial sector is insolvent bad banks have to be fundamentally insolvent. If $R_{1, F}^{*}<\infty$ investors are willing to finance banks that rescue which in particular implies that the expected net worth of a bank that rescues is strictly positive. In addition I have proved in the proof of Corollary 1 that all good banks rescue. If all bad banks rescue as well then $p_{1}^{*}=\alpha$ but since the aggregate financial sector is insolvent we would have $R_{1, F}^{*}=\infty$. If some bad banks don't rescue then Bayesian updating implies that $p_{0}^{*}=0$. Now, since bad banks are fundamentally insolvent we must have that $R_{0}^{*}=\infty$ and thus banks that do not rescue are not able to refinance their debt and their net worth is zero. But then bad banks would strictly prefer to rescue, which is a contradiction. We conclude that in equilibrium it has to be the case that $R_{1, F}^{*}=\infty$ and rescues are not financed.

Now, if $R_{1, N F}^{*}<R_{0}^{*}$ all banks rescue which implies by Bayesian updating that $p_{1}^{*}=\alpha$ and is sustained with the off-equilibrium belief $p_{0}^{*}=0$. If $R_{1, N F}^{*}=R_{0}^{*}$ then imposing the participation constraint of investors we have $p_{1}^{*}=p_{0}^{*}$ which implies that the same fraction of good banks and bad banks rescue. Finally if $R_{1, N F}^{*}>R_{0}^{*}$ then no bank would rescue the proof Corollary 1 shows this can never happen.

The expected net worth for every bank type $j=g, b$ is the same in the pooling with rescue case $R_{1, N F}^{*}=R\left(Z, D_{B}, \alpha\right)<R_{0}^{*}=R\left(Z, D_{B}, 0\right)=\infty$ and in the case $R_{1, N F}^{*}=R_{0}^{*}=$ $R\left(Z, D_{B}, \alpha\right)$ in which both types play mixed strategies in identical proportions.

Proof of Proposition 3 The results regarding the monotonicity of $\phi\left(D_{S}, D_{B}\right)$ with respect to $D_{S}$ and $D_{B}$ are an easy consequence of the characterization of equilibrium in Proposition 1 , the properties $\frac{\partial M_{b}(D, X, p)}{\partial D} \in(0,1)$ if $p>0$ and $\frac{\partial M_{b}(D, X, p)}{\partial p}>0$, and finally the fact that in equilibrium the fraction of bad banks that rescue is decreasing in investors' belief on the quality of rescuing banks. 
For $D_{B}=Z E\left[Y_{b}\right],(15)$ implies that the aggregate financial sector is solvent and thus in equilibrium rescues are financed and banks that rescue obtain a strictly positive expected net worth. Banks that do not rescue are perceived as bad and since $Z E\left[Y_{b}\right]=D_{B}$ they are not able to refinance their debt and their expected worth is zero. Hence, all banks find optimal to rescue and the equilibrium is pooling. This proves that there exist $\left(D_{S}, D_{B}\right) \in \mathcal{A}$ such that $\phi\left(D_{S}, D_{B}\right)=1$.

Let $D_{B}=0$ and $D_{S}^{\prime}=E\left[Y_{g}\right]$. Then by construction $\Pi_{g}\left(Z, D_{B}, 0\right)=\Pi_{g}\left(Z+1, D_{S}^{\prime}, 1\right)$ which means that for $R_{1, F}=R\left(Z+1, D_{S}^{\prime}, 1\right), R_{0}=0$ a good bank is indifferent between rescuing or not. Now, Lemma 2 implies that bad banks strictly prefer not to rescue, which means that $\Pi_{b}(Z, 0,0)>\Pi_{b}\left(Z+1, D_{S}^{\prime}, 1\right)$. By continuity, for $D_{S}$ slightly smaller we have

$$
\Pi_{b}(Z, 0,0)>\Pi_{b}\left(Z+1, D_{S}, 1\right) \text { and } \Pi_{g}(Z, 0,0)<\Pi_{g}\left(Z+1, D_{S}, 1\right),
$$

and for this pair $\left(D_{B}, D_{S}\right)$ the equilibrium is separating, i.e. $\phi\left(D_{S}, D_{B}\right)=0$.

A continuity argument finally implies that $\phi(\mathcal{A})=[0,1]$.

Proof of Proposition 4 Let us first highlight that for all $\tau \in[0,1]$ Assumptions 1, 2 and 3 are satisfied. Since for al $\tau$ we have $Z E\left[Y_{b}(\tau)\right] \geq D_{B}$, (15) implies that the aggregate financial sector is solvent for all $\tau$. We have thus:

$$
\Pi_{b}\left(Z+1, D_{B}+D_{S}, \alpha \mid \tau=1\right)>0=\Pi_{b}\left(Z+1, D_{B}, 0 \mid \tau=1\right) .
$$

By continuity, there exists $\tau^{\prime} \in(0,1)$ such that for all $\tau>\tau^{\prime}$ we have that:

$$
\Pi_{b}\left(Z+1, D_{B}+D_{S}, \alpha \mid \tau\right)>\Pi_{b}\left(Z+1, D_{B}, 0 \mid \tau\right) .
$$

And this means that for all $\tau>\tau^{\prime}$ the equilibrium is pooling.

Proof of Proposition 5 Let $\phi=\phi\left(D_{S}, D_{B}\right)$ be the fraction of bad banks that rescue in the no-ban economy. Using Proposition 3, the equations $\phi\left(D_{S}, D_{B}\right)=1, \phi\left(D_{S}, D_{B}\right)=0$ define implicitly two increasing functions $D_{B}=\mathcal{H}_{1}\left(D_{S}\right), \mathcal{H}_{0}\left(D_{S}\right)$ that describe all the pairs $\left(D_{S}, D_{B}\right)$ in the pooling and separating frontiers, respectively. We need some prelminary results before proceding to the proof of the proposition:

a. We have

$$
\mathcal{H}_{1}\left(\alpha E\left[Y_{g}\right]+(1-\alpha) E\left[Y_{b}\right]\right)=\mathcal{H}_{0}\left(E\left[Y_{g}\right]\right)
$$

b. If for $i=1,2,\left(D_{S}^{i}, D_{B}\right)$ is in the semiseparating region or in the pooling or separating frontiers then:

$$
\Pi_{j}\left(Z+1, D_{B}+D_{S}^{1}, p\left(\phi\left(\left(D_{S}^{1}, D_{B}\right)\right)\right)=\Pi_{j}\left(Z+1, D_{B}+D_{S}^{2}, p\left(\phi\left(\left(D_{S}^{2}, D_{B}\right)\right)\right) \text { for } j=g, b\right.\right.
$$


Indeed, by definition we have:

$$
\Pi_{b}\left(Z+1, D_{B}+D_{S}^{1}, p\left(\phi\left(\left(D_{S}^{1}, D_{B}\right)\right)\right)=\Pi_{b}\left(Z, D_{B}, 0\right)=\Pi_{b}\left(Z+1, D_{B}+D_{S}^{2}, p\left(\phi\left(\left(D_{S}^{2}, D_{B}\right)\right)\right),\right.\right.
$$

which implies that

$$
R\left(Z+1, D_{B}+D_{S}^{1}, p\left(\phi\left(\left(D_{S}^{1}, D_{B}\right)\right)\right)=R\left(Z+1, D_{B}+D_{S}^{2}, p\left(\phi\left(\left(D_{S}^{2}, D_{B}\right)\right)\right),\right.\right.
$$

and thus

$$
\Pi_{g}\left(Z+1, D_{B}+D_{S}^{1}, p\left(\phi\left(\left(D_{S}^{1}, D_{B}\right)\right)\right)=\Pi_{g}\left(Z+1, D_{B}+D_{S}^{2}, p\left(\phi\left(\left(D_{S}^{2}, D_{B}\right)\right)\right) .\right.\right.
$$

c. The function $M_{g}\left(Z, D_{B}, \alpha\right)-M_{g}\left(Z+1, D_{B}+D_{S}, \alpha\right)$ is increasing in $D_{B}$. in $y$ :

Indeed, since $\frac{f_{b}(y)}{p f_{g}(y)+(1-p) f_{b}(y)}$ is decreasing in $y$ the following function is also decreasing

$$
\frac{1-F_{b}(y)}{p\left(1-F_{g}(y)\right)+(1-p)\left(1-F_{b}(y)\right)}=\frac{\int_{y}^{\infty} f_{p}(z) d z}{\int_{y}^{\infty}\left(p f_{g}(z)+(1-p) f_{b}(z)\right) d z}
$$

Now, by linearity of the valuation function:

$$
V\left(Z+1, \frac{Z+1}{Z} R\left(Z, D_{B}, p\right), p\right)=\frac{Z+1}{Z} D_{B}<D_{B}+D_{S},
$$

where in the last inequality I have used that assumptions 1 and 2 imply in particular that $\frac{D_{B}}{Z}<D_{S}$. We deduce from here that $R\left(Z+1, D_{B}+D_{S}, p\right)>\frac{Z+1}{Z} R\left(Z, D_{B}, p\right)$ or equivalently $\frac{R\left(Z+1, D_{B}+D_{S}, p\right)}{Z+1}>\frac{R\left(Z, D_{B}, p\right)}{X}$. Using the expression for $\frac{\partial M_{b}(X, D, p)}{\partial D}$ in equation (27) and the monotonicity of the function in (34) we finally conclude that $\frac{\partial M_{b}\left(Z+1, D_{B}+D_{S}, p\right)}{\partial D}>\frac{\partial M_{b}\left(Z, D_{B}, p\right)}{\partial D}$ and taking into account that $M_{g}(X, D, \alpha)=-\frac{1-\alpha}{\alpha} M_{b}(X, D, \alpha)$ the result is proved.

Let us sequentially prove all the statements in the proposition:

\section{i) Expected welfare of vehicles debtholders}

Looking at (18) we observe that the expected welfare of vehicles debtholders is increasing in $\phi\left(D_{S}, D_{B}\right)$ and thus exists $\mathcal{M}\left(D_{S}\right)$ such that the ban increases the welfare of vehicles debtholders iff $D_{B} \leq \mathcal{M}\left(D_{S}\right)$. Let $D_{B}^{\prime}=\mathcal{H}_{1}\left(\alpha E\left[Y_{g}\right]+(1-\alpha) E\left[Y_{b}\right]\right)$. It suffices to prove that $D_{B}^{\prime}=\mathcal{M}\left(D_{S}\right)$ for all $D_{S}$.

Let $D_{S}^{1}=\alpha E\left[Y_{g}\right]+(1-\alpha) E\left[Y_{b}\right]$. By constructio the equilibrium for the pair $\left(D_{S}^{1}, D_{B}^{\prime}\right)$ is pooling. Now, since we have chosen $D_{S}^{1}$ so that the face value of debt is equal to the unconditional expected payoff of the vehicle's asset, the welfare of the vehicles' debtholders is unaffected by the introduction of the ban. Therefore, $D_{B}^{\prime}=\mathcal{M}\left(D_{S}^{1}\right)$.

Let $D_{S}^{2}=E\left[Y_{g}\right]$. Using (32) we have that $\left(D_{S}^{2}, D_{B}^{\prime}\right)$ is in the separating frontier and then using preliminary result $\mathrm{b}$ we have that for the pairs $\left(D_{S}^{i}, D_{B}^{\prime}\right), i=1,2$ the expected net 
worth of both types of banks in the no ban economy is the same. Henceforth, the aggregate expected net worth of bank for both pairs is the same in both no ban economies. This implies that the welfare of vehicles debtholders in both no ban economies is the same. Finally, since these agents are unaffected by the ban in the first economy they also are in the second, i.e. $D_{B}^{\prime}=\mathcal{M}\left(D_{S}^{2}\right)$.

From here using preliminary result b it is easy to prove that $D_{B}^{\prime}=\mathcal{M}\left(D_{S}\right)$ for all $D_{S}$.

\section{ii) Aggregate expected net worth of banks}

The result is equivalent to the one proved above for the welfare of vehicles debtholders

\section{iii) Expected net worth of bad banks}

If $\phi<1$ we must have $Z E\left[Y_{b}\right]>D_{B}$ and the type of some bad banks is revealed in the no ban economy and thus their expected net worth is $Z E\left[Y_{b}\right]-D_{B}$. Comparing with bad banks net expected worth in the ban case in (17) we conclude that the ban increases their net expected worth.

The argument for the pooling equilibrium case $\phi=1$ is slightly more involved. Let us suppose on the contrary that the ban reduces their expected worth, i.e. that

$$
\Pi_{b}\left(Z, D_{B}, \alpha\right) \leq \Pi_{b}\left(Z+1, D_{B}+D_{S}, \alpha\right)
$$

Using Lemma 2 with $R_{1, F}=R\left(Z+1, D_{B}+D_{S}, \alpha\right), R_{0}=R\left(Z, D_{B}, \alpha\right)$ we deduce that:

$$
\Pi_{g}\left(Z, D_{B}, \alpha\right)<\Pi_{g}\left(Z+1, D_{B}+D_{S}, \alpha\right)
$$

but this would imply that the aggregate expected net worth of banks decreases, which we have proved in i) is not the case when $\phi=1$.

\section{iv) Expected net worth of good banks}

Let us consider the inequality:

$$
M_{g}\left(Z, D_{B}, \alpha\right)-M_{g}\left(Z+1, D_{B}+D_{S}, \alpha\right) \geq E\left[Y_{g}\right]-D_{S}
$$

For every $D_{S}$ this inequality is satisfied for $D_{B}$ sufficiently high so that the equilibrium is pooling and the financial sector is close to aggregate insolvency. Since preliminary result c states that the LHS is increasing in $D_{B}$ there exists $\mathcal{G}\left(D_{S}\right)$ such that the inequality is satisfied iff $D_{B} \geq \mathcal{G}\left(D_{S}\right)$. In addition $\mathcal{G}\left(D_{S}\right)$ is decreasing in $D_{S}$.

Let $D_{S}^{1}$ be the intersection of $\mathcal{G}\left(D_{S}\right)$ and $\mathcal{H}_{1}\left(D_{S}\right)$ with the convention that $D_{S}^{1}=E\left[Y_{g}\right]$ if they do not intersect. ${ }^{45}$

\footnotetext{
${ }^{45}$ It can be proved that they intersect but since it is not essential for the rest of the proof of this proposition I skip this proof and allow for the possibility that they do not intersect in order for my arguments to be complete.
} 
I define:

$$
\mathcal{F}\left(D_{S}\right)=\left\{\begin{array}{l}
\mathcal{G}\left(D_{S}\right) \text { for } D_{S} \leq D_{S}^{1} \\
\mathcal{G}\left(D_{S}^{1}\right) \text { for } D_{S}>D_{S}^{1}
\end{array},\right.
$$

and I claim this function satisfies the properties stated in the proposition.

I state two results I use in the rest of the proof: first, we have $\mathcal{F}\left(D_{S}\right) \geq \mathcal{G}\left(D_{S}^{1}\right)=$ $\mathcal{H}_{1}\left(D_{S}^{1}\right)>\mathcal{H}_{1}\left(\alpha E\left[Y_{g}\right]+(1-\alpha) E\left[Y_{b}\right]\right)=D_{B}^{\prime}$; second, since preliminary result a states that $D_{B}^{\prime}=\mathcal{H}_{0}\left(E\left[Y_{g}\right]\right)$ we have that if $D_{B}^{\prime} \leq D_{B}<\mathcal{H}_{1}\left(D_{S}\right)$ the equilibrium is semiseparating.

Let $\left(D_{S}, D_{B}\right)$ be an admissible debt pair. If $D_{B} \geq \mathcal{H}_{1}\left(D_{S}\right)$ and the equilibrium is pooling, inequality (35) coincides with (19) and by construction good banks benefit from the ban iff $D_{B} \geq \mathcal{F}\left(D_{S}\right)=\mathcal{G}\left(D_{S}\right)$.

Let us suppose that $D_{B}<\mathcal{H}_{1}\left(D_{S}\right)$ and let us distinguish three cases:

If $D_{B} \geq \mathcal{F}\left(D_{S}\right)$ then since $\mathcal{F}\left(D_{S}\right) \geq D_{B}^{\prime}$ the equilibrium is semiseparating. There exists $D_{S}^{2} \geq D_{S}^{1}$ such that $D_{B}=\mathcal{H}_{1}\left(D_{S}^{2}\right)$, using preliminary result b we have

$$
\Pi_{g}\left(Z+1, D_{B}+D_{S}, p\left(\phi\left(\left(D_{S}, D_{B}\right)\right)\right)=\Pi_{g}\left(Z+1, D_{B}+D_{S}^{2}, p\left(\phi\left(\left(D_{S}^{2}, D_{B}\right)\right)\right) .\right.\right.
$$

Since the equilibrium in $\left(D_{S}^{2}, D_{B}\right)$ is pooling and $D_{B} \geq \mathcal{F}\left(D_{S}\right)=\mathcal{F}\left(D_{S}^{2}\right) \geq \mathcal{G}\left(D_{S}^{2}\right)$ we have

$$
\Pi_{g}\left(Z, D_{B}, \alpha\right) \geq \Pi_{g}\left(Z+1, D_{B}+D_{S}^{2}, \alpha\right)
$$

Combining the two previous inequalities and taking into account that $p\left(\phi\left(\left(D_{S}^{2}, D_{B}\right)\right)=\alpha\right.$ we conclude that good banks benefit from the ban as wanted.

If $D_{B}^{\prime} \leq D_{B}<\mathcal{F}\left(D_{S}\right)$ then the equilibrium is semiseparating. Also, since $D_{B}^{\prime}=$ $\mathcal{H}_{1}\left(\alpha E\left[Y_{g}\right]+(1-\alpha) E\left[Y_{b}\right]\right)$ there exists $D_{S}^{2}<D_{S}^{1}$ such that $D_{B}=\mathcal{H}_{1}\left(D_{S}^{2}\right)$. The steps followed above can be reproduced with the difference that in this case we have $D_{B}=\mathcal{H}_{1}\left(D_{S}^{2}\right)<\mathcal{G}\left(D_{S}^{2}\right)$ since $D_{S}^{2}<D_{S}^{1}$ and thus

$$
\Pi_{g}\left(Z, D_{B}, \alpha\right)<\Pi_{g}\left(Z+1, D_{B}+D_{S}^{2}, \alpha\right)
$$

from which we deduce that good banks do not benefit from the ban as wanted.

If $D_{B}<D_{B}^{\prime}$ then we have in particular that $D_{B}<\mathcal{F}\left(D_{S}\right)$. Also, the aggregate expected net worth of banks is reduced with the ban and since bad banks always benefit from the ban this implies in particular that the expected net worth of good banks is reduced with the ban as wanted. This concludes the proof.

Proof of Proposition 6 Since $M_{b}(X, D, p)$ is homogeneous of degree one we have:

$$
M_{b}\left(Z+\bar{Z}+1, D_{B}+(\bar{Z}+1) D_{S}, p\right)=(Z+\bar{Z}+1) M_{b}\left(1, \frac{D_{B}+(\bar{Z}+1) D_{S}}{Z+\bar{Z}+1}, p\right) .
$$


Assumptions 1 and 2 imply in particular that $\frac{D_{B}}{Z}<D_{S}$ and thus $\frac{D_{B}+(\bar{Z}+1) D_{S}}{Z+\bar{Z}+1}$ is increasing in $\bar{Z}$. Taking this into account and also that $\frac{\partial M_{b}(X, D, p)}{\partial D}>0$, equality above implies that $M_{b}\left(Z+\bar{Z}+1, D_{B}+(\bar{Z}+1) D_{S}, p\right)$ is increasing in $\bar{Z}$ and the proposition easily derives. 


\section{References}

Acharya, Viral, Philipp Schnabl, and Gustavo Suarez (2013), "Securitization without Risk Transfer," forthcoming, Journal of Financial Economics.

Arteta, Carlos, Mark Carey, Ricardo Correa, and Jason Kotter (2013), "Revenge of the Steamroller: ABCP as a Window on Risk Choices," Board of Governors of the Federal Reserve System, International Finance Discussion Papers, Number 1076.

Banks, Jeffrey S. and Joel Sobel (1987), "Equilibrium selection in signaling games," Econometrica, 55(3), 647-661.

Boot, Arnoud, Stuart Greenbaum, and Anjan Thakor (1993), "Reputation and Discretion in Financial Contracting," American Economic Review, 83, 1165-83.

Brady, Stephanie A., Ken E. Anadu, and Nathaniel R. Cooper (2012), "The stability of prime money market mutual funds: Sponsor support from 2007 to 2011," Federal Reserve Bank of Boston, Risk and Policy Analysis Working Papers, RPA 12-3.

Brunnermeier, Markus K. (2009), "Deciphering the Liquidity and Credit Crunch 20072008," Journal of Economic Perspectives, 23, 77-100.

Cho, In-Koo and David M. Kreps (1987), "Signaling Games and Stable Equilibria," Quarterly Journal of Economics, 102, 179-221.

Covitz, Daniel, Nellie Liang and Gustavo Suarez (2013), "The Evolution of a Financial Crisis: Collapse of the Asset-Backed Commercial Paper Market," Journal of Finance, $68,815-848$.

Dang, Tri Vi, Gary Gorton, and Bengt Holmstrom (2012), "Ignorance, Debt and Financial Crises," mimeo, Yale University.

DeMarzo, Peter and Darrell Duffie (1999), "A Liquidity-Based Model of Security Design," Econometrica, 67, 65-99.

Diamond, Douglas (1991), "Monitoring and Reputation: The Choice between Bank Loans and Directly Placed Debt," Journal of Political Economy, 99, 689-721.

Dinc, I. Serdar (2000), "Bank Reputation, Bank Commitment, and the Effects of Competition in Credit Markets," Review of Financial Studies, 13, 781-812. 
FitchIBCA (1999), "Implications of Securitization for Finance Companies," Financial Services Special Report, November 15, 1999.

Fleming, Michael J. and Nicholas J. Klagge (2010), "The Federal Reserve's Foreign Exchange Swap Lines," Current Issues in Economics and Finance, 6, N 4, NY Fed.

Fulghieri, Paolo and Dmitry Lukin (2001), "Information production, dilution costs, and optimal security design," Journal of Financial Economics, 61, 3-42.

Gennaioli, Nicola, Andrei Shleifer, and Robert Vishny (2013), "A Model of Shadow Banking," forthcoming, Journal of Finance.

Gorton, Gary B. (2010), "Slapped by the Invisible Hand: The Panic of 2007," Oxford University Press.

Gorton, Gary B. and Nicholas S. Souleles (2006), "Special Purpose Vehicles and Securitization," in Mark Carey and René M. Stulz, editors, The Risks of Financial Institutions, University of Chicago Press.

John, Kose and David C. Nachman (1985), "Risky Debt, Investment Incentives, and Reputation in a Sequential Equilibrium," Journal of Finance, 40, 863-878.

Kacperczyk, Marcin and Philipp Schnabl (2013), "How safe are money market funds?," Quarterly Journal of Economics, August 2013, 1073-1122.

Liikanen, Erkki, Chairman (2012), "High-level Expert Group on reforming the structure of the EU banking sector," European Commission, Brussels, October 2012.

Myers, Stewart C. (1977), "Determinants of Corporate Borrowing," Journal of Financial Economics, 5, 147-75.

Myers, Stewart C., and Nicholas S. Majluf (1984), "Corporate Financing and Investment Decisions when Firms Have Information that Investors Do Not Have," Journal of Financial Economics, 13, 187-221.

Nachman, David C. and Thomas H. Noe (1994), "Optimal design of securities under asymmetric information," Review of Financial Studies, 7, 1-44.

Office of the Comptroller of the Currency, Federal Deposit Insurance Corporation, Board of Governors of the Federal Reserve System, and the Office of Thrift Supervision (2002), "Interagency Guidance on Implicit Recourse in Asset Securitizations," May 23, 2002. 
Ordoñez, Guillermo (2013), "Confidence Banking and Strategic Default," working paper, University of Pennsylvania.

Parlatore, Cecilia (2013), "The Regulation of Money Market Funds: Adding Discipline to the Policy Debate," working paper, New York University.

Parlour, Christine A. and Guillaume Plantin (2008), "Loan Sales and Relationship Banking," Journal of Finance, 63, 1291-1314.

Poznar, Zoltan, Tobias Adrian, Adam Ashcraft, and Hayley Boesky (2012), "Shadow Banking," Federal Reserve Bank of New York, Staff Report No. 458.

Thakor, Anjan (2005), "Do loan commitments cause overlending?," Journal of Money, Credit, and Banking, 37, 1067-1099. 


\section{CEMFI WORKING PAPERS}

0801 David Martinez-Miera and Rafael Repullo: "Does competition reduce the risk of bank failure?".

0802 Joan Llull: "The impact of immigration on productivity".

0803 Cristina López-Mayán: "Microeconometric analysis of residential water demand".

0804 Javier Mencía and Enrique Sentana: "Distributional tests in multivariate dynamic models with Normal and Student $t$ innovations".

0805 Javier Mencía and Enrique Sentana: "Multivariate location-scale mixtures of normals and mean-variance-skewness portfolio allocation".

0806 Dante Amengual and Enrique Sentana: "A comparison of mean-variance efficiency tests".

0807 Enrique Sentana: "The econometrics of mean-variance efficiency tests: A survey".

0808 Anne Layne-Farrar, Gerard Llobet and A. Jorge Padilla: "Are joint negotiations in standard setting "reasonably necessary"?".

0809 Rafael Repullo and Javier Suarez: "The procyclical effects of Basel II".

0810 Ildefonso Mendez: "Promoting permanent employment: Lessons from Spain".

0811 Ildefonso Mendez: "Intergenerational time transfers and internal migration: Accounting for low spatial mobility in Southern Europe".

0812 Francisco Maeso and Ildefonso Mendez: "The role of partnership status and expectations on the emancipation behaviour of Spanish graduates".

0813 Rubén Hernández-Murillo, Gerard Llobet and Roberto Fuentes: "Strategic online-banking adoption".

0901 Max Bruche and Javier Suarez: "The macroeconomics of money market freezes".

0902 Max Bruche: "Bankruptcy codes, liquidation timing, and debt valuation".

0903 Rafael Repullo, Jesús Saurina and Carlos Trucharte: "Mitigating the procyclicality of Basel II".

0904 Manuel Arellano and Stéphane Bonhomme: "Identifying distributional characteristics in random coefficients panel data models".

0905 Manuel Arellano, Lars Peter Hansen and Enrique Sentana: "Underidentification?".

0906 Stéphane Bonhomme and Ulrich Sauder: "Accounting for unobservables in comparing selective and comprehensive schooling".

0907 Roberto Serrano: "On Watson's non-forcing contracts and renegotiation".

0908 Roberto Serrano and Rajiv Vohra: "Multiplicity of mixed equilibria in mechanisms: a unified approach to exact and approximate implementation".

0909 Roland Pongou and Roberto Serrano: "A dynamic theory of fidelity networks with an application to the spread of HIV / AIDS".

0910 Josep Pijoan-Mas and Virginia Sánchez-Marcos: "Spain is different: Falling trends of inequality".

0911 Yusuke Kamishiro and Roberto Serrano: "Equilibrium blocking in large quasilinear economies".

0912 Gabriele Fiorentini and Enrique Sentana: "Dynamic specification tests for static factor models". 
0913 Javier Mencía and Enrique Sentana: "Valuation of VIX derivatives".

1001 Gerard Llobet and Javier Suarez: "Entrepreneurial innovation, patent protection and industry dynamics".

1002 Anne Layne-Farrar, Gerard Llobet and A. Jorge Padilla: "An economic take on patent licensing: Understanding the implications of the "first sale patent exhaustion" doctrine.

1003 Max Bruche and Gerard Llobet: "Walking wounded or living dead? Making banks foreclose bad loans".

1004 Francisco Peñaranda and Enrique Sentana: "A Unifying approach to the empirical evaluation of asset pricing models".

1005 Javier Suarez: "The Spanish crisis: Background and policy challenges".

1006 Enrique Moral-Benito: "Panel growth regressions with general predetermined variables: Likelihood-based estimation and Bayesian averaging".

1007 Laura Crespo and Pedro Mira: "Caregiving to elderly parents and employment status of European mature women".

1008 Enrique Moral-Benito: "Model averaging in economics".

1009 Samuel Bentolila, Pierre Cahuc, Juan J. Dolado and Thomas Le Barbanchon: "Two-tier labor markets in the Great Recession: France vs. Spain".

1010 Manuel García-Santana and Josep Pijoan-Mas: "Small Scale Reservation Laws and the misallocation of talent".

1101 Javier Díaz-Giménez and Josep Pijoan-Mas: "Flat tax reforms: Investment expensing and progressivity".

1102 Rafael Repullo and Jesús Saurina: "The countercyclical capital buffer of Basel III: A critical assessment".

1103 Luis García-Álvarez and Richard Luger: "Dynamic correlations, estimation risk, and portfolio management during the financial crisis".

1104 Alicia Barroso and Gerard Llobet: "Advertising and consumer awareness of new, differentiated products".

1105 Anatoli Segura and Javier Suarez: "Dynamic maturity transformation".

1106 Samuel Bentolila, Juan J. Dolado and Juan F. Jimeno: "Reforming an insideroutsider labor market: The Spanish experience".

1201 Dante Amengual, Gabriele Fiorentini and Enrique Sentana: "Sequential estimation of shape parameters in multivariate dynamic models".

1202 Rafael Repullo and Javier Suarez: "The procyclical effects of bank capital regulation".

1203 Anne Layne-Farrar, Gerard Llobet and Jorge Padilla: "Payments and participation: The incentives to join cooperative standard setting efforts".

1204 Manuel Garcia-Santana and Roberto Ramos: "Dissecting the size distribution of establishments across countries".

1205 Rafael Repullo: "Cyclical adjustment of capital requirements: A simple framework". 
1206 Enzo A. Cerletti and Josep Pijoan-Mas: "Durable goods, borrowing constraints and consumption insurance".

1207 Juan José Ganuza and Fernando Gomez: "Optional law for firms and consumers: An economic analysis of opting into the Common European Sales Law".

1208 Stéphane Bonhomme and Elena Manresa: "Grouped patterns of heterogeneity in panel data".

1209 Stéphane Bonhomme and Laura Hospido: "The cycle of earnings inequality: Evidence from Spanish Social Security data".

1210 Josep Pijoan-Mas and José-Víctor Ríos-Rull: "Heterogeneity in expected longevities".

1211 Gabriele Fiorentini and Enrique Sentana: "Tests for serial dependence in static, non-Gaussian factor models".

1301 Jorge De la Roca and Diego Puga: "Learning by working in big cities".

1302 Monica Martinez-Bravo: "The role of local officials in new democracies: Evidence from Indonesia".

1303 Max Bruche and Anatoli Segura: "Debt maturity and the liquidity of secondary debt markets".

1304 Laura Crespo, Borja López-Noval and Pedro Mira: "Compulsory schooling, education and mental health: New evidence from SHARELIFE".

1305 Lars Peter Hansen: "Challenges in identifying and measuring systemic risk".

1306 Gabriele Fiorentini and Enrique Sentana: "Dynamic specification tests for dynamic factor models".

1307 Diego Puga and Daniel Trefler: "International trade and institutional change: Medieval Venice's response to globalization".

1308 Gilles Duranton and Diego Puga: "The growth of cities".

1309 Roberto Ramos: "Banning US foreign bribery: Do US firms win?".

1310 Samuel Bentolila, Marcel Jansen, Gabriel Jiménez and Sonia Ruano: "When credit dries up: Job losses in the Great Recession".

1401 Felipe Carozzi and Luca Repetto: "Sending the pork home: Birth town bias in transfers to Italian municipalities".

1402 Anatoli Segura: "Why did sponsor banks rescue their SIVs? A signaling model of rescues". 